\title{
Ferulic acid-based reactive core-shell latex by seeded emulsion polymerization
}

Wing Sze Jennifer. $\mathrm{Li}^{\mathrm{a}}$, Vincent Ladmiral ${ }^{\mathrm{a}}$, Hisaaki Takeshima ${ }^{\mathrm{b}}$, Kotaro Satoh ${ }^{\mathrm{b}}$, Masami Kamigaito ${ }^{\mathrm{b}}$, Mona Semsarilar ${ }^{c}$, Claire Negrell ${ }^{a}$, Patrick Lacroix-Desmazes ${ }^{a}$, Sylvain Caillol ${ }^{a *}$

a ICGM, Université de Montpellier, CNRS, ENSCM, Montpellier, France.

${ }^{b}$ Department of Molecular and Macromolecular Chemistry, Graduate School of Engineering, Nagoya University, Nagoya 464-8603, Japan.

c Institut Européen des Membranes (UMR 5635, ENSCM-CNRS-UM), Université de Montpellier, C.C. 047, Place E. Bataillon, Montpellier, France.

*sylvain.caillol@enscm.fr

\section{Abstract}

A recently revisited biobased styrenic monomer, acetyl-protected 4-vinylguaiacol (AC4VG), was used for the synthesis of partially biobased, functional core-shell polymers. P(S-co-BA)@PAC4VG and PBA@PAC4VG latex particles with PAC4VG shell were prepared using a two-step seeded radical emulsion polymerization process. The $\mathrm{P}(\mathrm{S}-\mathrm{Co}-\mathrm{BA})$ and $\mathrm{PBA}$ seed particles were synthesized first, and the AC4VG monomer was subsequently added as a pre-emulsion over time. The aqueous emulsion polymerizations were carried out at $10 \mathrm{wt}$. $\%$ solids at $80{ }^{\circ} \mathrm{C}$ using ammonium persulfate as radical initiator and sodium dodecyl sulfate as surfactant. These polymerizations resulted in colloidally stable latexes with high monomer conversions (>95\%). The resulting particles were $80-90 \mathrm{~nm}$ in diameter (intensity-average) and TEM observations revealed core-shell and partially encapsulated particle morphologies. Up to 70\% of the acetoxy groups of PAC4VG in the P(S-co-BA)@PAC4VG latex were deprotected under mild basic conditions over 18 hours to produce core-shell polymers decorated with phenolic functions on their surface. This deprotection procedure did not adversely affect the particle size or colloidal stability of the latex. Finally, partially biobased phenolic networks (phenolic resins) were produced from these functional core-shell particles by crosslinking with glyoxal, a naturally-sourced dialdehyde.

\section{Introduction}

Latex polymers are indispensable materials in today's world and are used in a wide variety of industries. Their properties which can be tuned via the choice of monomers and polymer structures enable these materials to fulfil the requirements of a large range of applications, including but not limited to films, coatings, adhesives, cosmetics, and drug delivery. ${ }^{1,2,3}$ In the last couple of decades, spherical polymer particles with more and more complex morphologies and structures have been 
developed. ${ }^{4,5,6,7,8}$ One of the most versatile of these morphologies is the core-shell particle, which allows the preparation of latex with superior properties that would not otherwise be achievable from a homogeneous mixture of the original components. The successful synthesis of functional core-shell particles is highly dependent on the polymerization technique and conditions used. ${ }^{9}$ As the name implies, core-shell latexes are composed of at least two polymers: one located at the centre of the particle, the core, and another distributed on the surface of this core, ultimately forming a shell. ${ }^{10}$ This class of polymer latex is very attractive, especially for use in high value-added applications such as drug delivery, controlled release of active substances, ${ }^{11}$ or nanostructured materials for electrochemical applications for example. ${ }^{12}$

In core-shell latex synthesis, the composition of the shell is of utmost importance as it ultimately affects the reactivity and stability of the polymer particle. However, the combination of two or more polymers in latex synthesis can also result in other morphologies, such as moon-like, snowman-like, framboidal or dumbbell-like structures. ${ }^{8}$ Depending on the application, precise control over the particle morphology can be very important for imparting the desired properties to the final polymer. The advantage of using core-shell particles is that the combination of two or more components generates new functionality and properties which often cannot be achieved from the individual components. ${ }^{13,14,15}$ For instance, Lapeyre et al. ${ }^{16}$ developed a multi-responsive, core-shell microgel consisting of a temperature-responsive poly( $N$-isopropylacrylamide) PNIPAM core and a glucoseresponsive P(NIPAM-co-APBA) shell (APBA stands for acrylamidophenylboronic acid) used for the delivery of insulin in the human body. In the paints and coatings industry, a UV-and water-resistant paint was developed by AkzoNobe ${ }^{17}$ without sacrificing crucial physical and mechanical properties.

Among the different techniques which can be used to synthesize core-shell particles, emulsion polymerization is the most common method. ${ }^{9}$ In emulsion polymerization, the final latex particle size and morphology are determined largely by the nucleation and growth stages of the polymerization as well as individual polymer surface properties. ${ }^{18}$ In the simplest system, water (the dispersed phase), monomer (oil phase), surfactant, and initiator make up the starting emulsion. The polymerization progresses until all of the monomer has been consumed. ${ }^{19}$ To synthesize core-shell particles, a semi-continuous, two-step seeded emulsion polymerization is commonly employed. ${ }^{5,20}$ The first step of this procedure is the formation of small latex known as seed particles. In the second step, the shell is grown on the surface of the seed particles leading to the core-shell morphology. However, the final particle morphology ultimately depends on the nature of the polymers used and the polymerization conditions, as thermodynamic and kinetic factors come into play in shaping the final morphology. ${ }^{19}$ The use of seed particles helps to minimize the variability in particle formation during the second stage of the polymerization (maintaining the particle number constant and a low 
variation in size and composition between particles). In many cases, a pre-emulsion is used to feed in the second monomer. This favours a smooth transition of the monomer into the latex environment.

One of the most significant barriers to the sustainable development of polymer materials is the lack of use of renewable building blocks and the use of toxic or volatile organic compounds. The need for environmentally benign, biobased materials is becoming more important as the consequences of global warming become more critical. Most of the common monomers used nowadays still come from petroleum-based sources. The search for "greener" substitutes to existing petroleum-based materials has been a key research topic in recent years as naturally-occurring compounds have been used more extensively in the preparation of biobased polymers. ${ }^{21}$ Satoh et al. ${ }^{22}$ for example, have prepared a number of biobased polymers using renewable monomers such as terpenes, phenylpropanoids, or itaconic derivatives. Vinyl monomers derived from vegetable oils (such as soybean and sunflower oils) have been successfully used in emulsion polymerization systems to produce water-resistant films. ${ }^{23}$ Moreno et al. ${ }^{24}$ have also developed polymerizable fatty acid derivatives, such as methacrylated oleic acid, for binders in coating applications.

Naturally-occurring phenolic compounds are of great interest as a viable replacement for styrene and to prepare biobased polymers with high thermal and mechanical performance. Biobased aromatic phenols have been derived from lignin, by demethylation to generate catechol moieties. ${ }^{25-27}$ One of our teams has recently prepared a variety of novel functional styrenic monomers from ferulic acid, ${ }^{21}$ a natural and abundant phenolic compound found in plant cell walls. ${ }^{28}$ Since phenols can react with radicals, the phenolic functions of these monomers were protected prior to polymerization to allow for their radical polymerization. Deprotection was performed under mild conditions postpolymerization to regain functionality. These protected vinylguaiacols and vinylcatechols were also successfully used in controlled radical solution polymerization. ${ }^{21}$ Recently, our team paved the way for emulsion polymerization of biobased aromatic monomers. Indeed, our group synthesized two new cardanol-derived monomers and demonstrated their use in emulsion and miniemulsion polymerization for the preparation of latex and functional films for coatings applications. ${ }^{29,30}$ In the present work, the two-stage seeded aqueous emulsion polymerization of an acetyl-protected 4vinylguaiacol (4-acetoxy-3-methoxy styrene, AC4VG), ${ }^{21,31}$ styrene and $n$-butyl acrylate to produce biobased functional core-shell particles is presented. Polymer latexes containing a styrenic/acrylic core and a biobased AC4VG shell were prepared and their properties and morphologies examined. These biobased latexes were subsequently deprotected under mild conditions and crosslinked in the presence of glyoxal, a dialdehyde obtained from natural resources, ${ }^{32}$ to prepare resole type phenolic resins. The use of a biobased shell component allows for the partial replacement of petroleum-based 
monomers in the latex, and provides the latex with valuable functional groups (here phenols) available for further chemical reactions.

\section{Experimental}

\section{Materials}

Sodium dodecyl sulfate (SDS, >99\%, Aldrich), ammonium persulfate (APS, >99\%, Aldrich), toluene (>99\%, Aldrich), methanol (>99\%, Fisher), triethylamine (>99\%, Aldrich), glyoxal (40 wt. \% aqueous solution, Aldrich), and hydroquinone monomethyl ether (MEHQ, >98\%, Aldrich) were used as received. 2,2'-azobis(2-methylpropionitrile) (AIBN, 98\%, Fluka) was purified by recrystallization in methanol and dried under vacuum before use. Styrene $(S,>99 \%$, Aldrich) and $n$-butyl acrylate (BA, $>99 \%$, Aldrich) were purified by distillation at $30{ }^{\circ} \mathrm{C}$ under vacuum at $10^{-2} \mathrm{mbar}$ prior to use. The monomer 4-acetoxy-3-methoxy styrene (AC4VG) was synthesized according to the procedure described previously. ${ }^{21}$ Deionized water (DIW) $\left(1 \mu \mathrm{S} \cdot \mathrm{cm}^{-1}\right)$ was obtained using a D8 ion exchange demineralizer from A2E Affinage de L'Eau.

\section{Methods}

\section{Solution polymerization}

The solution homopolymerization of AC4VG and copolymerization of styrene and $n$-butyl acrylate were carried out in toluene. The homopolymerization of AC4VG was performed as follows: AC4VG $(2.00 \mathrm{~g}, 10.4 \mathrm{mmol})$ was added to toluene $(5 \mathrm{~g})$ in a two-neck round bottom flask sealed with a septum and equipped with a reflux condenser. A $30 \mathrm{~min} \mathrm{~N}_{2}$ purge was carried out to remove any traces of oxygen from the reaction medium. AIBN $(0.04 \mathrm{~g}$, $0.24 \mathrm{mmol}, 2 \mathrm{wt}$. \% with respect to monomer) was dissolved into a small amount of toluene $(1 \mathrm{~g})$ and the resulting solution was purged with $\mathrm{N}_{2}$ for $5 \mathrm{~min}$. The flask containing the reaction mixture was subsequently immersed in an oil bath at $70{ }^{\circ} \mathrm{C}$. The stirring speed was set at $300 \mathrm{rpm}$. The AIBN solution was then injected via a syringe into the reaction mixture to start the polymerization.

For the copolymerization, the following quantities were used: styrene $(8 \mathrm{~g}, 76.8 \mathrm{mmol}, 80 \mathrm{wt}$. $\%$ of total monomer), $n$-butyl acrylate $(2 \mathrm{~g}, 15.6 \mathrm{mmol}, 20 \mathrm{wt}$. \% of total monomer), AIBN $(0.4 \mathrm{~g}, 2.47 \mathrm{mmol}, 4 \mathrm{wt}$. \% with respect to monomer) and toluene $(25 \mathrm{~g})$. The copolymerization was performed following the procedure described above for the homopolymerization of AC4VG.

\section{Seed Latex Preparation}


The poly(butyl acrylate) PBA and poly(styrene-co-butyl acrylate) P(S-co-BA) seed latexes were synthesized as follows. The emulsion polymerization of PBA was carried out in a $150 \mathrm{~mL}$ doublewalled glass reactor equipped with a U-shaped glass stirring rod. For a $10 \mathrm{wt}$. \% latex emulsion, SDS $(0.20 \mathrm{~g}, 69 \mathrm{mmol})$ and $\mathrm{Na}_{2} \mathrm{CO}_{3}(0.10 \mathrm{~g}, 0.94 \mathrm{mmol})$ were combined with DIW $(100 \mathrm{~g})$ and purged with argon for $30 \mathrm{~min}$. $n$-Butyl acrylate $(10 \mathrm{~g}, 78 \mathrm{mmol})$ was purged with argon for $15 \mathrm{~min}$ and subsequently added dropwise into the reaction mixture under agitation. APS $(0.20 \mathrm{~g}, 0.88 \mathrm{mmol}$, $2 \mathrm{wt}$. \% with respect to monomer) was combined with $1 \mathrm{~g}$ of DIW and purged with argon for $5 \mathrm{~min}$. Meanwhile, the reactor was heated to $80^{\circ} \mathrm{C}$. Once the reactor temperature reached $80^{\circ} \mathrm{C}$, the solution of APS was injected via a syringe to begin the reaction. The polymerization was carried out under argon atmosphere and agitation at $300 \mathrm{rpm}$ for 4 hours. Samples were withdrawn periodically to monitor monomer conversion by gravimetry. The copolymerizations of styrene and $n$-butyl acrylate were performed using the same procedure, keeping the total mass of monomers at $10 \mathrm{~g}$ and a styrene/n-butyl acrylate mass ratio at $80 / 20$.

\section{Seeded emulsion polymerization}

The seeded emulsion polymerizations were carried out using the previously synthesized seed latexes with two semi-continuous feeds, one consisting of monomer, DIW, and surfactant in the form of a pre-emulsion, and one consisting of an aqueous solution of the initiator. To prepare the core-shell polymers, $15 \mathrm{~g}$ of the PBA or P(S-co-BA) seed latex (10 wt. \% solids) was added to the reactor and purged with argon for $30 \mathrm{~min}$. A pre-emulsion was prepared by combining AC4VG (2 g, $10.4 \mathrm{mmol}$ for P(S-Co-BA)@PAC4VG; 3 g, 15.6 mmol for PBA@PAC4VG), SDS (0.04 g, 0.14 mmol), and deionized water (11 g) and purged with argon for $30 \mathrm{~min}$. APS (0.04 g, $18 \mathrm{mmol})$ was combined with deionized water $(4 \mathrm{~g})$ and purged with argon for $10 \mathrm{~min}$. Meanwhile, the reactor was heated to $80^{\circ} \mathrm{C}$. Once the reactor temperature reached $80^{\circ} \mathrm{C}$, one third of the APS solution was injected via a syringe to begin the reaction and the pre-emulsion was fed to the reaction mixture via a syringe pump (Model LA100 from Landgraf Laborsysteme) over 3 hours. Simultaneously, the remaining two thirds of the APS solution was fed to the reaction mixture via a syringe pump (Model KDS-100-CE from KD Scientific) over 3.5 hours. The polymerization was carried out under argon atmosphere and agitation (300 rpm) for 4 hours. Final monomer conversion was measured using ${ }^{1} \mathrm{H}$ NMR spectroscopy (Equation S1 in ESI).

\section{Deprotection of PAC4VG and (PS-co-PBA)@PAC4VG}

The deprotection of PAC4VG synthesized by solution polymerization (and subsequently purified by precipitation in methanol and dried at $40^{\circ} \mathrm{C}$ under vacuum) was carried out under acidic conditions in acetone to convert $-\mathrm{OCOCH}_{3}$ groups to $-\mathrm{OH}$ groups. PAC4VG $(0.2 \mathrm{~g})$ was dissolved in acetone $(25 \mathrm{~mL})$ 
with $11 \mathrm{M} \mathrm{HCl}$ solution $(0.5 \mathrm{~mL})$ and stirred for 24 hours at $65^{\circ} \mathrm{C}$ in a round-bottom flask sealed with a septum. The deprotected polymer was combined with DIW $(7 \mathrm{~g})$, filtered, washed with DIW, and finally dried in an oven at $40{ }^{\circ} \mathrm{C}$. The deprotection of PAC4VG in the final copolymer latex was carried out under basic conditions in a hydromethanolic medium. P(S-co-BA)@PAC4VG latex (5 g, 10 wt. \% solids, 1 molar equiv.) was added to methanol ( $4.5 \mathrm{~g}$, equal parts to water) with triethylamine $(1.1 \mathrm{~g}$, 7 molar equiv.) and stirred at $35^{\circ} \mathrm{C}$ for 18 hours. The remaining solvent and by-products (acetic acid, methyl acetate, triethylamine) were subsequently removed by rotary evaporator at $30{ }^{\circ} \mathrm{C}$.

\section{Synthesis of phenol-aldehyde resins}

Resole type phenol-aldehyde resins were produced using the deprotected latex and glyoxal. The deprotected latex ( $2 \mathrm{~g}, 10 \mathrm{wt}$. \% solids) was mixed with glyoxal (0.04 g, $40 \mathrm{wt}$. \% aqueous solution) at a 1:1 aldehyde:phenol molar ratio, and $\mathrm{KOH}(0.08 \mathrm{~g}, 10 \mathrm{wt}$. \% solution) was added as basic catalyst at 4 wt. \% of polymer. The reaction mixture was placed in aluminum pans and cured in a ventilated oven for 2 hours at $60^{\circ} \mathrm{C}, 2$ hours at $120^{\circ} \mathrm{C}$, and 1 hour at $140{ }^{\circ} \mathrm{C}$.

\section{Characterizations}

Monomer conversions of $\mathrm{P}(\mathrm{S}-\mathrm{CO}-\mathrm{BA})$ and PBA latex were determined by gravimetry using an MLS moisture analyzer from Kern heating to $160^{\circ} \mathrm{C}$. Approximately $2 \mathrm{~g}$ of latex was placed in an aluminum sample pan tared with a small amount (a few grains) of MEHQ to inhibit any polymerization reactions that may occur during heating.

Nuclear Magnetic Resonance spectroscopy (NMR). Chemical structures and monomer conversions were determined by ${ }^{1} \mathrm{H}$ NMR spectroscopy on a Bruker Avance $400 \mathrm{MHz}$ spectrometer at $21{ }^{\circ} \mathrm{C}$. External reference was trimethylsilane (TMS) with chemical shifts given in ppm. For the determination of monomer conversion of AC4VG in solution polymerization, approximately $0.1 \mathrm{~mL}$ of the reaction solution was withdrawn via syringe, placed into an NMR tube and diluted with $0.5 \mathrm{~mL}$ of $\mathrm{CDCl}_{3}$. Monomer conversions of AC4VG in emulsion polymerizations were determined by ${ }^{1} \mathrm{H}$ NMR by diluting $0.1 \mathrm{~mL}$ of latex in $0.5 \mathrm{~mL}$ of deuterated THF-d8.

Fourier Transform Infrared spectroscopy (FTIR). FTIR spectra were acquired on a Thermo Scientific Nicolet 6700 FTIR spectrometer using the attenuated total reflection module (ATR), and were analyzed using an OMNIC Series 8.2 software from Thermo Scientific.

Differential Scanning Calorimetry (DSC). DSC analysis was performed on a Netzsch DSC 200 F3 instrument calibrated with noble metals (biphenyl, indium, tin, bismuth, zinc, cesium chloride) and checked against an indium sample as reference. The following heating/cooling cycle was used: first heating ramp from $-100^{\circ} \mathrm{C}$ to $150^{\circ} \mathrm{C}$ at $20^{\circ} \mathrm{C} / \mathrm{min}$, cooling stage from $150^{\circ} \mathrm{C}$ to $-100^{\circ} \mathrm{C}$ at $20^{\circ} \mathrm{C} / \mathrm{min}$, 
isotherm plateau at $-100{ }^{\circ} \mathrm{C}$ for $10 \mathrm{~min}$, second heating ramp from $-100^{\circ} \mathrm{C}$ to $150^{\circ} \mathrm{C}$ at $20^{\circ} \mathrm{C} / \mathrm{min}$, and a last cooling stage from $150{ }^{\circ} \mathrm{C}$ to $20^{\circ} \mathrm{C}$.

Thermogravimetric analysis (TGA). Thermogravimetric analysis was performed on a Q50 TGA from TA Instruments using a temperature ramp of $10{ }^{\circ} \mathrm{C} \mathrm{min}-1$ from $20{ }^{\circ} \mathrm{C}$ to $580^{\circ} \mathrm{C}$ under nitrogen flow of $60 \mathrm{~mL} \mathrm{~min}{ }^{-1}$ in an aluminum pan. Results were analyzed using Universal Analysis V4.5A software.

Transmission Electron Microscopy (TEM). TEM was performed on a Jeol 1200EXII transmission electron microscope at an operating voltage of $100 \mathrm{kV}$ with images captured with a Quemesa camera from Olympus Soft Imaging Solutions. Particle sizes measured by TEM were performed using the measurelT software from Olympus Soft Imaging Solutions $\mathrm{GmbH}$ on an average of 50 particles. Standard deviations are respectively $\mathrm{P}\left(\mathrm{S}_{85}-\mathrm{CO}-\mathrm{BA}_{15}\right)$ : 8.4\%; $\mathrm{P}\left(\mathrm{S}_{37}-\mathrm{CO}-\mathrm{BA}_{6}\right) @ \mathrm{PAC} \mathrm{VVG} \mathrm{G}_{57}$ : 5.1\%;PBA: 9.4\%; $\mathrm{PBA}_{30} @ \mathrm{PAC4VG}_{70}: 8.8 \%$. One drop of latex was diluted in $5 \mathrm{~mL}$ of DIW and subsequently placed onto a Formvar-coated, 300-mesh copper grid, stabilized with evaporated carbon film for TEM analysis and left to dry under air prior to analysis. For stained samples, the prepared grids were placed over a freshly prepared 1 wt. \% aqueous solution of $\mathrm{RuO}_{4}$ and exposed to its vapors for a duration of 10 minutes prior to analysis.

Dynamic Light Scattering (DLS). Dynamic light scattering particle size measurements were performed on a Vasco 3 nanoparticle size analyzer from Cordouan Technologies at $25^{\circ} \mathrm{C}$ using the cumulant model. The laser power, time interval, and number of channels were modified accordingly to obtain a good ACF (autocorrelation function). Standard deviation (less than 10\%) is given for each measurement. Samples for DLS measurements were prepared by diluting one drop of latex with $5 \mathrm{~mL}$ of deionized water. An average of 10 measurements was taken.

Zeta Potential. Zeta potential measurements were performed on a Wallis zeta potential analyzer from Cordouan Technologies at $25^{\circ} \mathrm{C}$ using the Smoluchowski approximation. Samples for zeta potential measurements were prepared by diluting one drop of latex with $5 \mathrm{~mL}$ of deionized water. An average of 10 measurements was taken.

Contact Angle. Contact angle measurements were performed on a contact angle system OCA15Pro from Data Physics equipped with an electronic syringe unit. Measurements were performed using the sessile drop method at $25^{\circ} \mathrm{C}$ and contact angles were measured using the SCA20 software. Deionized water and methylene iodide were used as the polar and non-polar liquids for the contact angle measurements.

Gel Content Measurements. The gel content of the polymers was measured by placing $30 \mathrm{mg}$ of polymer, previously dried in a ventilated oven at $50{ }^{\circ} \mathrm{C}$ for 4 hours, in a Teflon pocket which was subsequently immersed in $30 \mathrm{~mL}$ of THF for 24 hours, then dried in a ventilated oven at $50{ }^{\circ} \mathrm{C}$ for 24 hours. The gel content was calculated based on the initial and final polymer mass according to Equation (1) below. 


$$
\text { Gel content }=\frac{m_{\text {final }}}{m_{\text {initial }}} \times 100 \%
$$

\section{Results and Discussion}

\section{Seeded emulsion copolymerization}

To synthesize well-defined, partially biobased, core-shell polymer particles featuring acetyl-protected 4-vinylguaiacol (AC4VG) units in the shell, a seeded emulsion polymerization approach was used. The seed latex consisted of a copolymer of styrene and $n$-butyl acrylate, at a weight ratio of 80:20 (S:BA). This composition was chosen so that the $T_{\mathrm{g}}$ of the resulting copolymer would fall within the $50-70$ ${ }^{\circ} \mathrm{C}$ range. Ideally, for coating applications, the $T_{\mathrm{g}}$ of the core should be lower. However for proof of concept purposes, a $T_{\mathrm{g}}$ of ca. $50-70{ }^{\circ} \mathrm{C}$ was chosen to facilitate the characterization of the polymer particles.

In the first step, the emulsion copolymerization of styrene and $n$-butyl acrylate was carried out at 80 ${ }^{\circ} \mathrm{C}$ using SDS as surfactant and APS as initiator at solids content of $10 \mathrm{wt} . \%$. The styrene and $n$-butyl acrylate monomer conversions reached $86 \%$ and $61 \%$ respectively after 3.5 hours, at which point the reaction was stopped. In a seed, residual monomers improve preservation of emulsion polymers without addition of preservative and improve compatibilization during shell polymerization. The intensity-average hydrodynamic diameter of the seed particles was determined by DLS to be $57 \mathrm{~nm}$. TEM micrographs of this latex confirmed this size (ca. $50 \mathrm{~nm}$, Figure 1). Note that the diameter estimated from TEM is slightly smaller than that measured by DLS because DLS measurements take into account the electrical double layer surrounding the particles in suspension. ${ }^{1} \mathrm{H}$ NMR analysis allowed the calculations of the final P(S-co-BA) copolymer molar composition of S:BA $=87: 13$ (mass composition of $\mathrm{S}: \mathrm{BA}=85: 15)$. The final $\mathrm{pH}$ of this latex was 8.7.

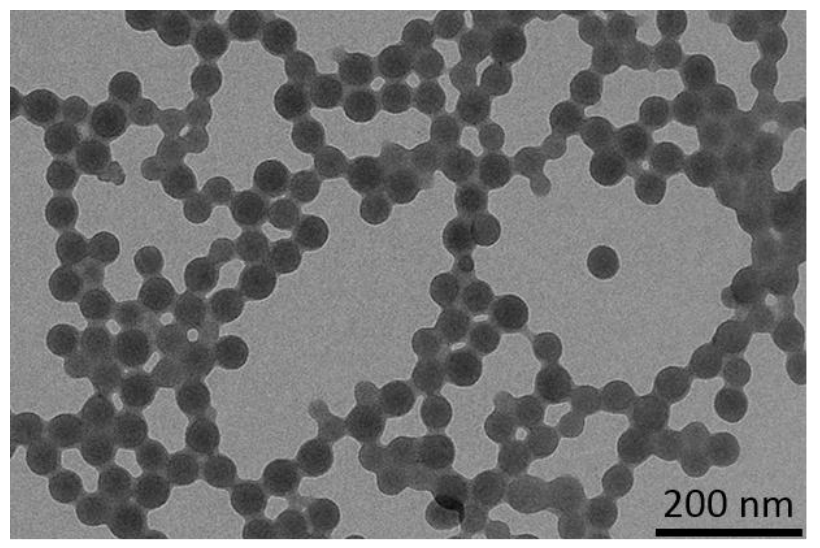


In the second step, AC4VG was added to the P(S-co-BA) seed latex as a pre-emulsion under starvedfeed conditions over a period of 3 hours with a continuous addition of initiator (APS) over 3.5 hours. It should be noted that the $\mathrm{P}(\mathrm{S}-\mathrm{CO}-\mathrm{BA})$ seed latex was not purified beforehand and therefore small quantities of residual styrene and $n$-butyl acrylate monomer remain in the seed latex (approximately $12 \mathrm{wt}$. \% with respect to AC4VG). The polymerization was left to proceed for one additional hour so that the conversion was almost complete (>95\%). The overall solids content was kept at $10 \mathrm{wt} . \%$ and the $\mathrm{pH}$ of the final latex was 2.3. Particle size measurements by DLS revealed an intensity-average hydrodynamic diameter of $80 \mathrm{~nm}$, which was also confirmed by TEM $(75 \mathrm{~nm})$. The number of particles in final latex $\left(1.5 \times 10^{16}\right)$ remained unchanged compared to that in the seed latex $(1.4 \mathrm{x}$ $10^{16}$ ), indicating that no aggregation nor re-nucleation occurred (Equations S2 and S3 in ESI). Intensity, volume, and number average particle hydrodynamic diameter distributions are provided in Figures S1, S2, and S3, respectively. The overall molar and mass compositions of the polymer were determined by ${ }^{1} \mathrm{H}$ NMR (Figure 2 ) to be S:BA:AC4VG $=49: 8: 43$ and 37:6:57 respectively.

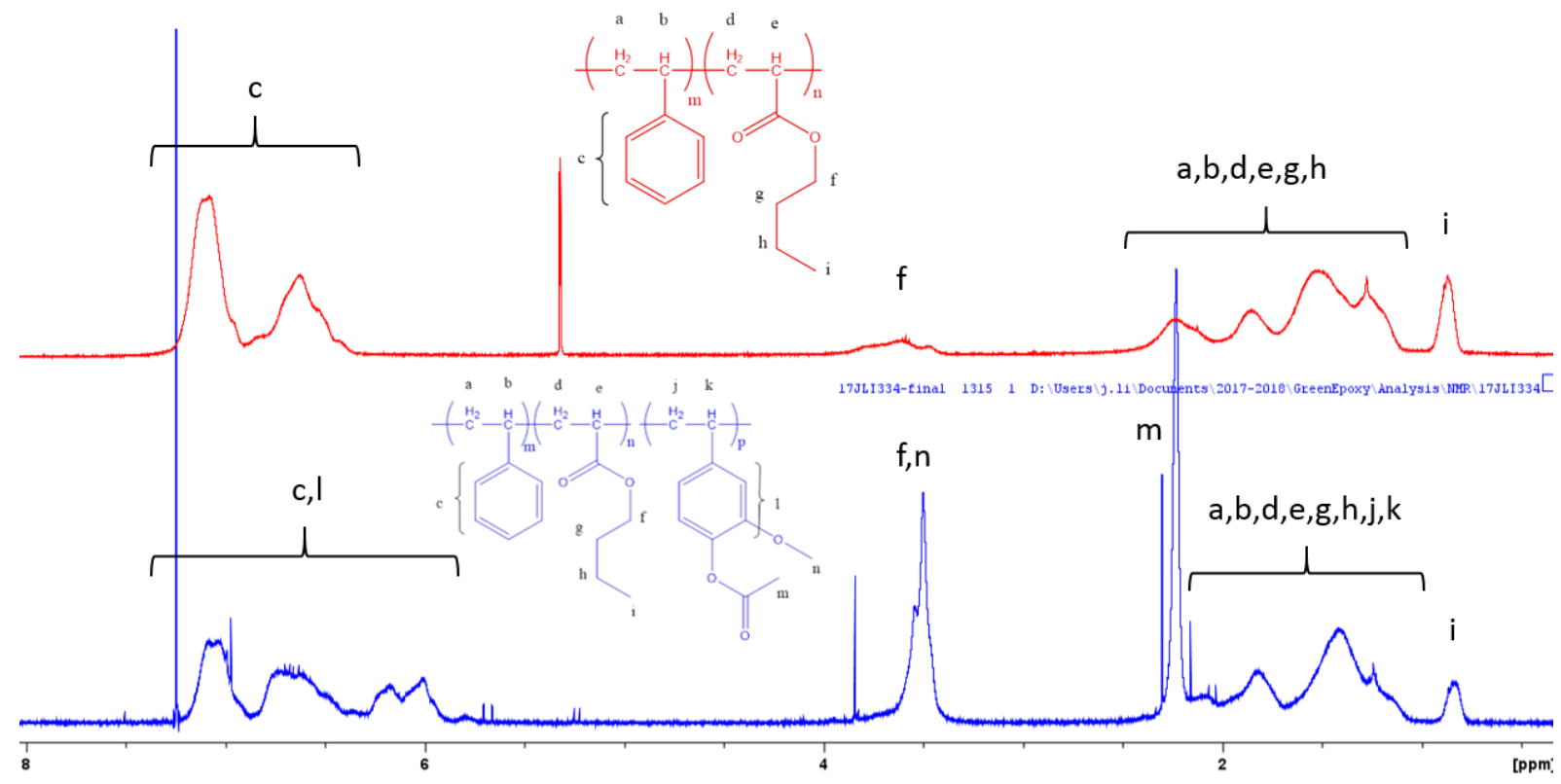

Figure 2: ${ }^{1} \mathrm{H} N \mathrm{NM}$ spectra of $\mathrm{P}\left(\mathrm{S}\right.$-co-BA) seed polymer in $\mathrm{CD}_{2} \mathrm{Cl}_{2}$ and $\mathrm{P}\left(\mathrm{S}\right.$-co-BA)@PAC4VG polymer in $C D C \mathrm{C}_{3}$. These NMR spectra were acquired on vacuum dried polymers; residual $S$ and $B A$ monomers thus do not show.

A second polymer, without aromatics in the core, was also prepared to help the characterization and understanding of the particle morphologies. Using a PBA seed latex, PBA@PAC4VG core-shell latex was prepared using the same procedure. Dynamic light scattering analysis revealed an intensityaverage hydrodynamic diameter of the seed particles of $65 \mathrm{~nm}$ after 3.5 hours ( Conv $_{\mathrm{BA}}=92 \%$ ). Following the polymerization of AC4VG, the intensity-average hydrodynamic diameter of the resulting latex was determined by DLS to be $90 \mathrm{~nm}$ (near complete conversion). TEM analysis of this final latex (Figure 3) confirmed both the seed and final particle sizes (60 nm and $80-90 \mathrm{~nm}$ respectively). Again, the number of particles did not change in the final latex $\left(1.1 \times 10^{16}\right)$ compared to 
that in the seed $\left(1.0 \times 10^{16}\right)$; hence it can be concluded that no aggregation or re-nucleation took place during the polymerization of AC4VG. The overall polymer molar and mass compositions were determined by ${ }^{1} \mathrm{H}$ NMR (Figure 4) to be PBA:PAC4VG $=40: 60$ and 30:70 respectively. The final polymer properties are summarized in Table 1 . The seed latex exhibit neutral $\mathrm{pH}$ since $\mathrm{Na}_{2} \mathrm{CO}_{3}$ was added during synthesis to avoid the low $\mathrm{pH}$ caused by homolytic cleavage of persulfate leading to the formation of $\mathrm{HSO}_{4}{ }^{-39}$

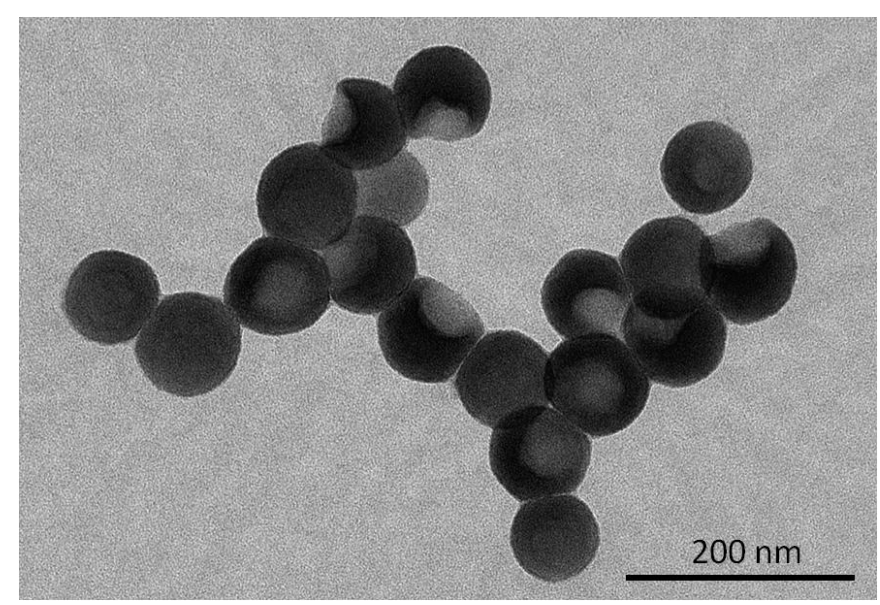

Figure 3: TEM image of PBA@PAC4VG latex particles; aromatic groups of PAC4VG are stained by $\mathrm{RuO}_{4}$ vapours.

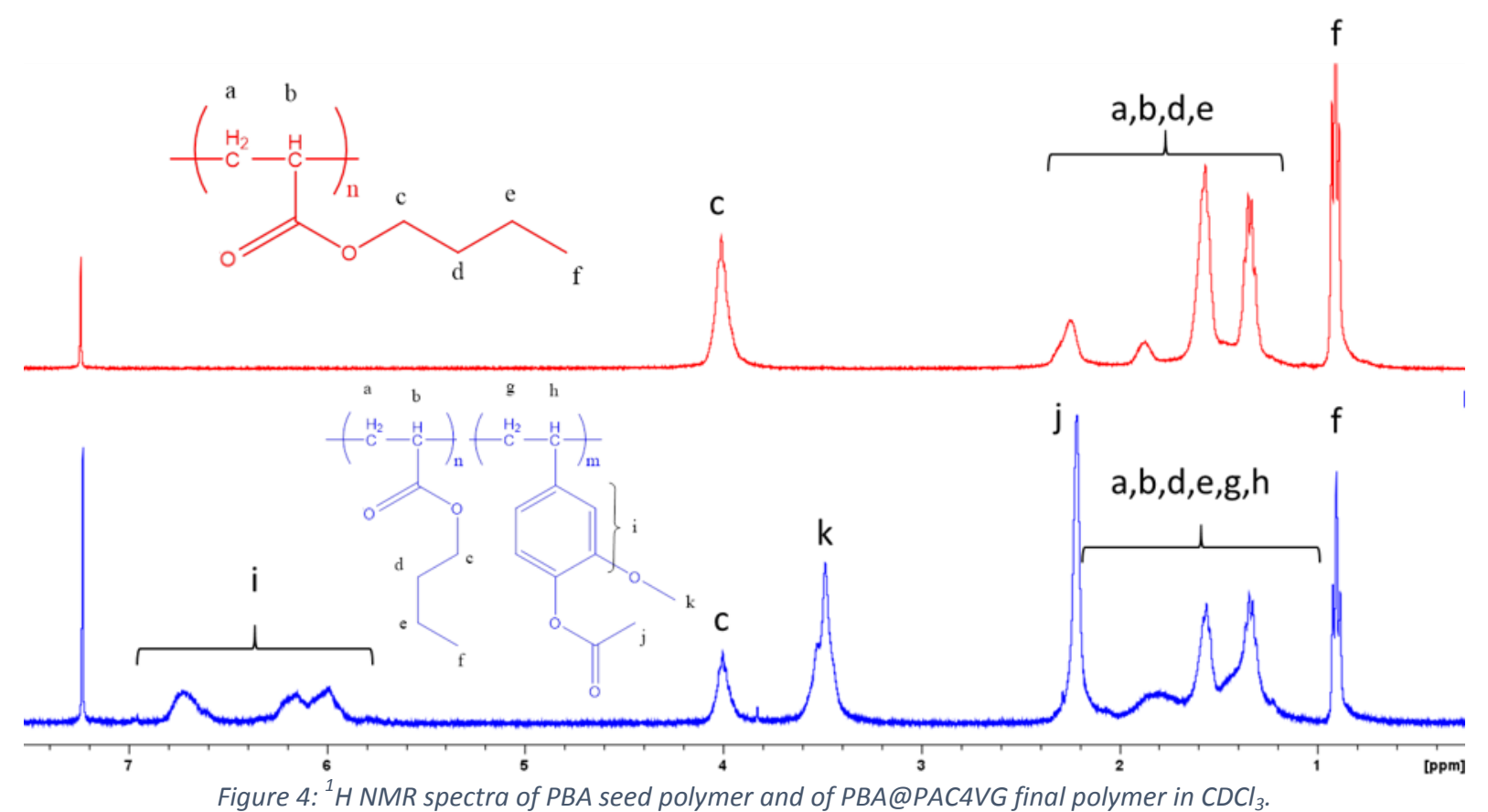

Table 1: Summary of the polymer synthesis and properties.

\begin{tabular}{cccccc}
\hline Polymer & Conversion (\%) & $\begin{array}{c}\text { Particle Diameter }^{\mathrm{d}} \\
(\mathrm{nm})\end{array}$ & $\begin{array}{c}\text { Standard } \\
\text { Deviation }^{\mathrm{d}}(\%)\end{array}$ & PDI $^{\mathrm{e}}$ & $\mathrm{pH}^{\mathrm{a}}$ \\
\hline $\mathrm{P}\left(\mathrm{S}_{85}-\mathrm{CO}-\mathrm{BA}_{15}\right)$ & $86^{\mathrm{a}}, 61^{\mathrm{b}}$ & $57 / 50$ & 7.0 & 0.06 & 8.7
\end{tabular}




\begin{tabular}{cccccc}
\hline $\mathrm{P}\left(\mathrm{S}_{37}-\mathrm{CO}-\mathrm{BA}_{6}\right) @ P A C 4 V G_{57}$ & $>95^{\mathrm{c}}$ & $80 / 75$ & 7.9 & 0.24 & 2.3 \\
$\mathrm{PBA}$ & 92 & $65 / 60$ & 8.9 & 0.12 & 6.8 \\
$\mathrm{PBA}_{30} @ P A C 4 V G_{70}$ & $>95^{\mathrm{c}}$ & $90 / 80-90$ & 8.6 & 0.05 & 2.8
\end{tabular}

Note: Monomer conversions of ${ }^{a}$ styrene, ${ }^{b} n$-butyl acrylate, ${ }^{c} A C 4 V G .{ }^{d}$ Intensity-average hydrodynamic diameter determined by dynamic light scattering / diameter measured by TEM. ${ }^{e}$ PDI calculated according to ISO13321 standard for DLS measurement. Subscripts in the polymer formula indicate polymer weight fractions.

\section{Particle Morphology}

The final particle morphologies are important as they define, to a large extent, the properties of the polymer latex. In the present case, PAC4VG is desired on the exterior of the particle to enable further functionalization of the polymer latex. Gonzalez-Ortiz et $a l^{33}$ proposed a model based on the surface tensions $\gamma_{i j}$ at the interfaces of the three-phase system of the latex (seed polymer, second stage polymer, and water), that enables the prediction of the final particle thermodynamic equilibrium morphology. Interfacial surface tensions were calculated using a method developed by Wu et al., ${ }^{34}$ and surface free energies of the synthesized polymers were calculated using Owen's equation ${ }^{35}$ (Equation S4 and Equation S5 respectively in ESI).

Contact angles on the polymer surfaces measured using a polar liquid $\left(\mathrm{H}_{2} \mathrm{O}\right)$ and a non-polar liquid $\left(\mathrm{CH}_{2} \mathrm{I}_{2}\right.$, methylene iodide) were used to calculate the surface energies due to hydrogen bonding $\left({ }_{\mathrm{s}}{ }^{\mathrm{P}}\right)$ and to dipole-dipole interactions $\left(\gamma_{s}{ }^{D}\right)$, that make up the overall surface energy of the polymer, $\gamma_{s}$ (Table S1). The calculated interfacial surface energies were then used to determine the resulting equilibrium morphology using the Gonzales-Ortiz model according to the variables $\mathrm{U}$ and $\mathrm{T}$ (see Table $S 2, U=\gamma_{12} / \gamma_{2 w}$ and $T=\left|\gamma_{2 w}-\gamma_{12}\right| / \gamma_{1 w}$, where $\gamma_{12}$ is the interfacial tension between species 1 and 2 , and $\gamma_{1 \mathrm{w}}$ and $\gamma_{2 \mathrm{w}}$ are the interfacial tensions between water and species 1 and 2 respectively). The four equilibrium morphologies (individual polymer particles, core-shell particles, inverted core-shell particles, and occluded morphology) are represented in Figure 5 along with the predicted morphologies for the P(S-co-BA)@PAC4VG and PBA@PAC4VG latexes. For the P(S-co-BA)@PAC4VG latex, the thermodynamic equilibrium morphology was predicted to be core-shell (with a P(S-co-BA) core). However, partial encapsulation leading to acorn or dumbbell morphologies was also possible because the values of $U$ and $T$ were very close to the requirements for such morphologies. For the PBA@PAC4VG latex, partial encapsulation of the core was predicted although slight deviations in the values of $U$ and $T$ could also indicate core-shell and inverted core-shell structures. However in a polymerization system, kinetic factors also come into play and these may interfere with the ability for the particles to develop the thermodynamic equilibrium morphology. ${ }^{36}$ 


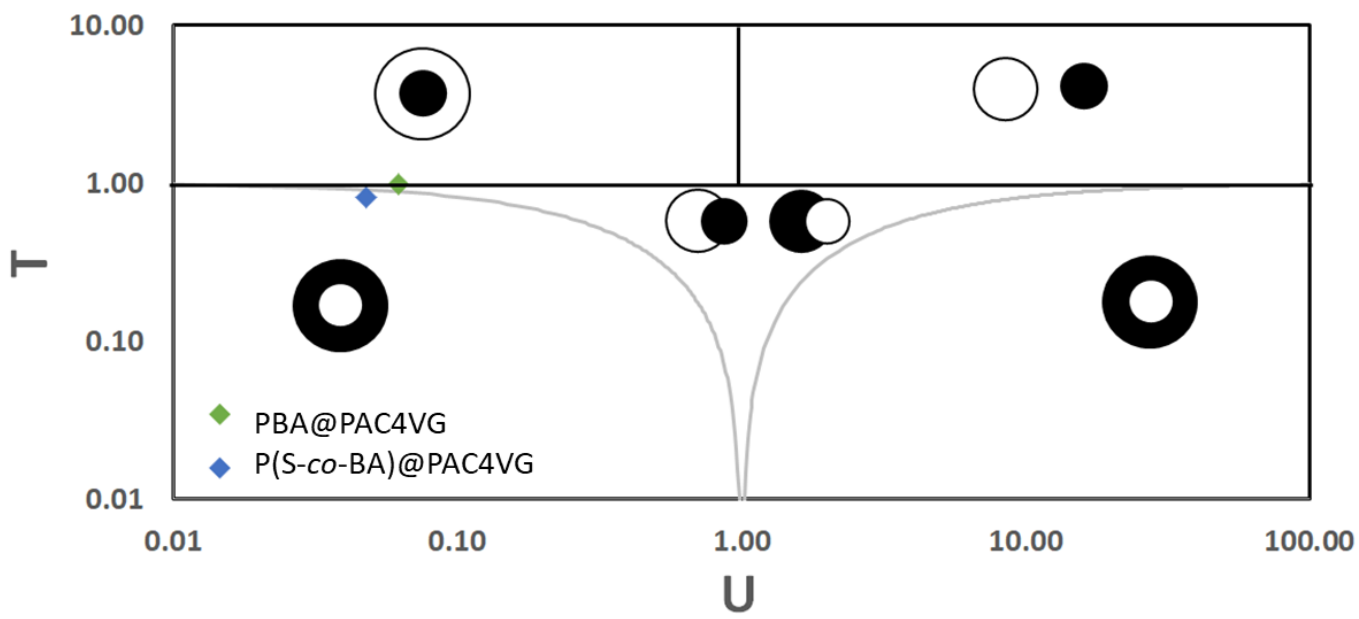

Figure 5: Thermodynamic equilibrium morphology prediction according to the model of Gonzalez-Ortiz $\left(U=\gamma_{12} / V_{2 W}, T=\left(V_{2 W}\right.\right.$ $\left.\left.v_{12}\right) / v_{1 w}\right) .^{33}$ 1=PBA for PBA@PAC4VG and 1=P(S-co-BA) for P(S-co-BA)@PAC4VG, 2=PAC4VG, W=water.

For PBA@PAC4VG particles, transmission electron microscopy was performed to confirm the final particle morphology. Selective staining was successfully performed using $\mathrm{RuO}_{4}$ to reveal the location of the different polymer phases (Figure 3). TEM micrographs revealed partially encapsulated particles consisting of a PBA core partially encapsulated by a PAC4VG shell (Janus-like), similar to the thermodynamic equilibrium morphology predicted using the model of Gonzalez-Ortiz. ${ }^{33}$ DSC analysis in Figure 6 showed three glass transition temperatures at $-48{ }^{\circ} \mathrm{C}$, at $52{ }^{\circ} \mathrm{C}$, and at $117{ }^{\circ} \mathrm{C}$ for PBA@PAC4VG. This indicates that the latex is composed of three phases: two pure polymer phases (PBA core ${ }^{37}$ at $-50^{\circ} \mathrm{C}$ and PAC4VG shell ${ }^{21}$ at $110^{\circ} \mathrm{C}$ ), and a third phase likely located the interface of the core and shell. The third phase might be favoured by the presence of residual monomer in the PBA seed latex (less than 10 wt. \%) leading to the formation of a small amount of P(BA-co-AC4VG) copolymer having an intermediate $T_{\mathrm{g}}\left(52{ }^{\circ} \mathrm{C}\right)$. Such a $\mathrm{P}(\mathrm{BA}-\mathrm{co}-\mathrm{AC} 4 \mathrm{VG})$ copolymer can act as compatibilizer at the PBA/PAC4VG interface (i.e. decrease $\gamma_{12}$ ), thus favouring the encapsulation of the PBA core by the PAC4VG shell. Since AC4VG is added under starved conditions, it suggests that the seed PBA is essentially not swollen by AC4VG during the growth of the PAC4VG phase. According to Stubbs et al., ${ }^{36}$ the combination of the starved feed condition (no radical penetration of the core) and $T_{\text {gPACAVG }}>T_{\text {reaction }}$ is also favouring a core-shell structure. Thus, the particles with a PBA core encapsulated by a PAC4VG shell observed in TEM suggest the influence of kinetic factors interfering with the establishment of the thermodynamic equilibrium morphology. 

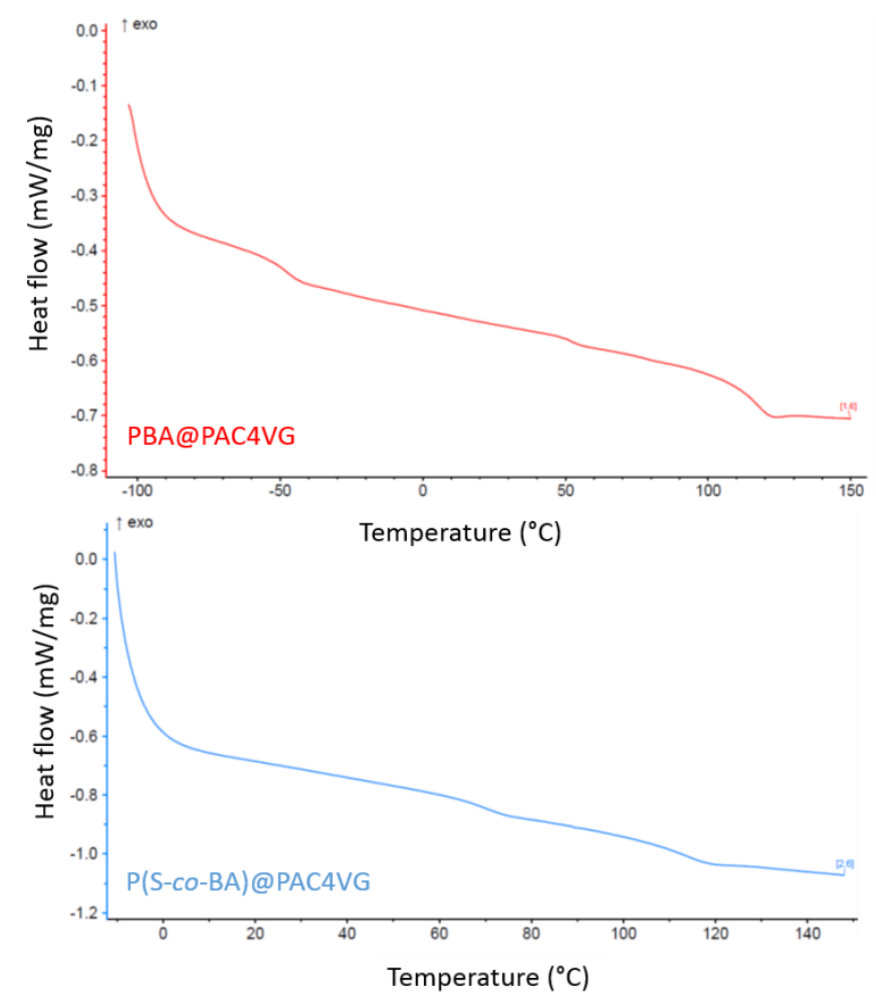

Figure 1: DSC thermograms of PBA@PAC4VG and P(S-co-BA)@PAC4VG.

In the case of the P(S-Co-BA)@PAC4VG latex, due to the presence of aromatic groups in both the seed and the targeted shell polymers, selective staining could not be used to identify the location of the two polymer phases by TEM. However, considering the predicted equilibrium morphology based on interfacial tensions of the polymer phases with water, and comparing the $T_{\mathrm{g}}$ of the polymers and the reaction temperature, a particle morphology can be estimated. The $1^{\text {st }}$ stage copolymerization of styrene and $n$-butyl acrylate produced, as expected, a homogeneous copolymer, as indicated by the DSC analysis in Figure 6, which showed only one $T_{\mathrm{g}}$ at $71^{\circ} \mathrm{C}$. This value is in reasonable agreement with the theoretical estimation of the $T_{\mathrm{g}}$ of a $\mathrm{P}\left(\mathrm{S}_{85}-\mathrm{CO}_{-}-\mathrm{BA}_{15}\right)$ copolymer according to the Fox-Flory equation $\left(T_{\mathrm{g} \text {, calculated }}=64{ }^{\circ} \mathrm{C}\right.$, Equation S6). Pursuing the $2^{\text {nd }}$ stage polymerization of AC4VG under starved-feed conditions, a second glass transition temperature at $116{ }^{\circ} \mathrm{C}$ was observed, corresponding to the $T_{\mathrm{g}}$ of pure PAC4VG. ${ }^{21}$ These DSC measurements clearly indicate the presence of two separate polymer phases and the absence of a mixed phase. Since no radical penetration of the core should occur under starved feed conditions and $\gamma_{\mathrm{P}(\mathrm{S}-\mathrm{Co}-\mathrm{BA})-\mathrm{W}}>{ }_{\gamma_{\mathrm{PACAVG}}-\mathrm{W}}$, both the considerations of the flow chart proposed by Stubbs et al. ${ }^{36}$ and the diagram predicted using the Gonzalez-Ortiz model ${ }^{33}$ support the formation of core-shell particles. Therefore, PAC4VG is expected to be located at the exterior of the particles. In addition, the TEM images (Figure S5) showed spherical particles compatible with the complete encapsulation of the P(S-co-BA) core by the PAC4VG shell. Acetoxy groups are thus likely accessible for further functionalization. A summary of the predicted and observed morphologies can be found in Table 2. 
Table 2: Glass transition temperatures and particle morphology predictions of P(S-co-BA)@PAC4VG and PBA@PAC4VG.

\begin{tabular}{cccccc}
\hline Polymer & $\begin{array}{c}T_{\mathrm{g}} \text { of seed } \\
\text { polymer } \\
\left({ }^{\circ} \mathrm{C}\right)\end{array}$ & $\begin{array}{c}\boldsymbol{T}_{\mathrm{g}} \text { of final } \\
\text { latex }\left({ }^{\circ} \mathrm{C}\right)\end{array}$ & $\begin{array}{c}\text { Thermodynamically } \\
\text { predicted } \\
\text { morphology }\end{array}$ & $\begin{array}{c}\text { Kinetically } \\
\text { predicted } \\
\text { morphology }^{36}\end{array}$ & $\begin{array}{c}\text { Observed TEM } \\
\text { morphology }\end{array}$ \\
\hline P(S-CO-BA) & 73 & 71,116 & $\begin{array}{c}\text { Core-shell } \\
\text { @PAC4VG }\end{array}$ & Core-shell & N/A \\
PBA@PAC4VG & -47 & $\begin{array}{c}-47,52, \\
117\end{array}$ & $\begin{array}{c}\text { Acorn or dumbbell } \\
\text { morphologies, } \\
\text { partial encapsulation }\end{array}$ & $\begin{array}{c}\text { Gradient } \\
\text { core-shell }\end{array}$ & $\begin{array}{c}\text { Core-shell, } \\
\text { partial } \\
\text { encapsulation }\end{array}$
\end{tabular}

\section{Deprotection of PAC4VG and P(S-Co-BA)@PAC4VG}

The deprotection of the acetoxy groups of PAC4VG (synthesized by solution polymerization) was performed in acetone using $11 \mathrm{M} \mathrm{HCl}$ at $65^{\circ} \mathrm{C}$ for 24 hours, followed by a purification by precipitation in methanol. ${ }^{1} \mathrm{H}$ NMR analysis was used to confirm the conversion of the acetate groups into hydroxyl groups (Figure 7). The disappearance of the characteristic acetate peak at $2.22 \mathrm{ppm}$ was observed and accompanied by the appearance of a new peak at 6.96-7.48 ppm, assigned to hydroxyl groups. Integration of these signals indicated that the deprotection proceeded at a steady rate, reaching $40 \%$ at the end of 3 hours, before slowing down and finally reaching $85 \%$ at the end of 24 hours. The kinetics of the deprotection reaction is shown in Figure 8. FTIR analysis (Figure S5) also confirmed the appearance of hydroxyl groups evidenced by the broad IR band at approximately $3000-3500 \mathrm{~cm}^{-1} .{ }^{38}$ Thermogravimetric analysis of PAC4VG before and after deprotection showed slight changes in the decomposition profile as summarized in Table 3 (thermograms available in Figure S4 of ESI). Indeed, the deprotection reaction removes fragile bonds on phenols which leads to a slight higher thermal stability.

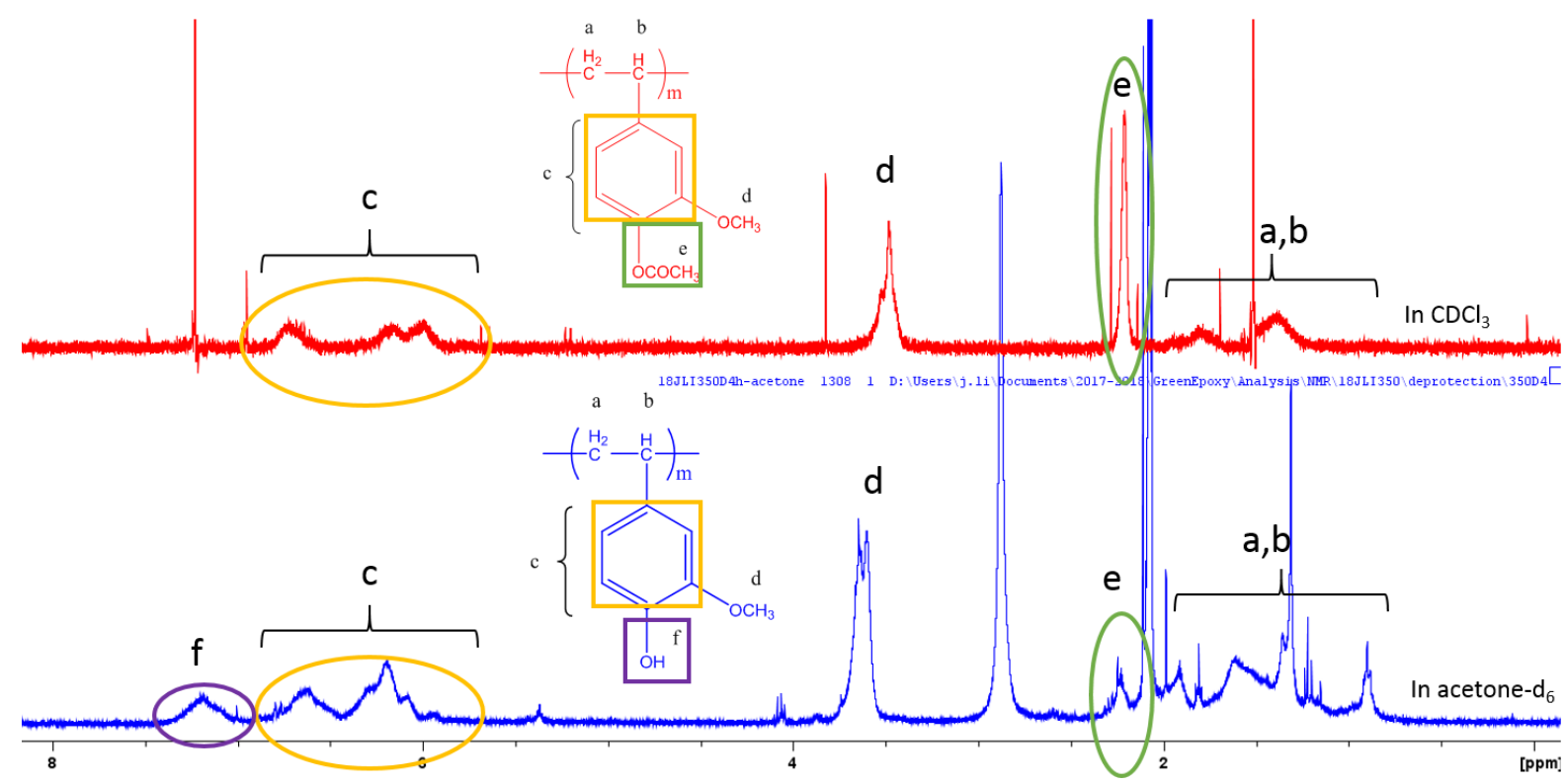


Figure 2: ${ }^{1} \mathrm{H}$ NMR analysis of PAC4VG before (in $\mathrm{CDCl}_{3}$ ) and after deprotection (in acetone-d6).

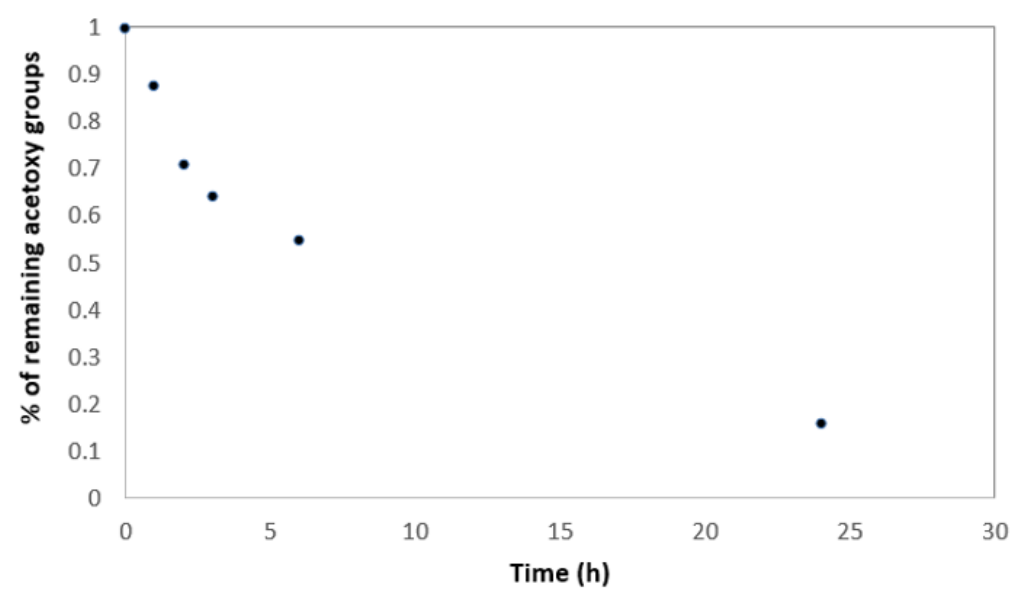

Figure 8: Reaction-time profile for the deprotection of PAC4VG.

Table 3: Thermogravimetric analysis of protected and deprotected PAC4VG.

\begin{tabular}{ccc}
\hline Sample ID & $T_{\mathrm{d}, 2 \%}\left({ }^{\circ} \mathrm{C}\right)^{\mathrm{a}}$ & $T_{\mathrm{d}, 10 \%}\left({ }^{\circ} \mathrm{C}\right)^{\mathrm{b}}$ \\
\hline PAC4VG & 106 & 203 \\
PAC4VG (after deprotection) & 120 & 221
\end{tabular}

${ }^{a}$ Temperature corresponding to $2 \%$ weight loss

${ }^{\mathrm{b}}$ Temperature corresponding to $10 \%$ weight loss

Although deprotection of the acetoxy groups of PAC4VG proceeded with high yields under acidic conditions, this protocol failed with the latex particles (low yield). Therefore, the deprotection of the acetoxy groups on the surface of the latex particles was carried out under basic conditions. For the polymer P(S-Co-BA)@PAC4VG, the deprotection was carried out in methanol with triethylamine at 35 ${ }^{\circ} \mathrm{C}$ for 18 hours. ${ }^{1} \mathrm{H}$ NMR analysis (Figure 9) revealed a decrease of the $-\mathrm{OCOCH}_{3}$ signal at $2.22 \mathrm{ppm}$, compared to the $\mathrm{CH}_{3}$ signal of PBA at $0.91 \mathrm{ppm}$, accompanied by an increase of the aromatic signals (5.91-7.63 ppm). The hydroxyl signal could not be observed correctly as it overlaps with the aromatic peaks of PS. Integration of the aromatic signals indicates that about $70 \%$ of acetate groups were deprotected. The appearance of hydroxyl groups was confirmed by FTIR analysis, although the characteristic IR band at $3500 \mathrm{~cm}^{-1}$ was weaker than that observed for P4VG (Figure S6 and S7). Complete deprotection was not achieved likely due to the fact that part of the acetoxy groups are "buried" inside the hydrophobic phase of the polymer particles and thus not readily accessible to TEA or methanolate. After deprotection, the remaining organic solvents and by-products were removed by rotary evaporator. The concentrated latex was then redispersed in deionized water to produce a stable latex. TEM analysis on the deprotected latex showed no changes in the particle size: polymer particles of approximately $80 \mathrm{~nm}$ were observed (see Figure 10). 


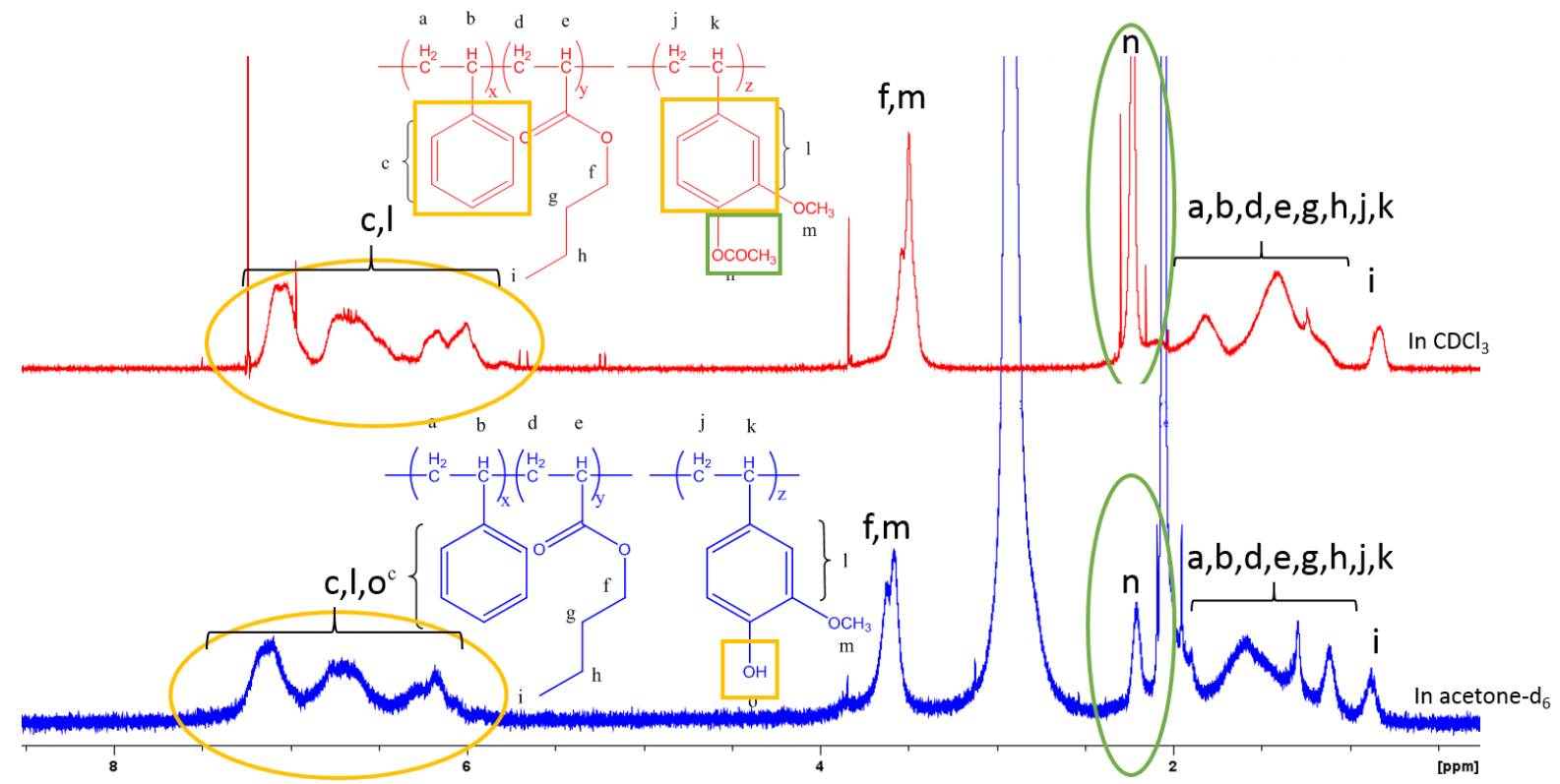

Figure 9: ${ }^{1} \mathrm{H} N M R$ analysis of $P(S-c o-B A) @ P A C 4 V G$ before (in $\mathrm{CDCl}_{3}$ ) and after deprotection (in acetone-d6).

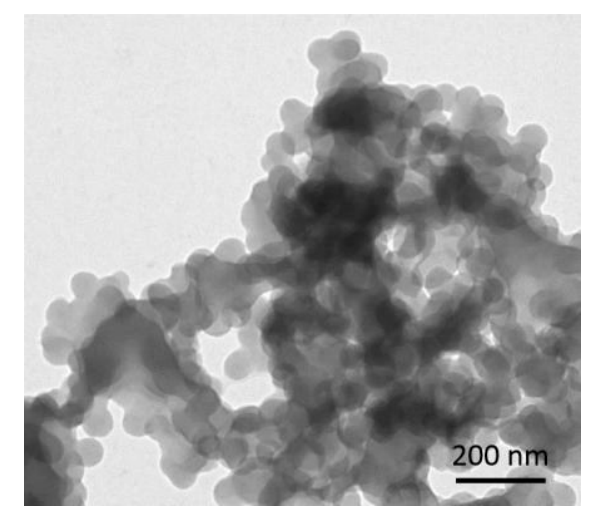

Figure 10: TEM micrograph of deprotected P(S-co-BA)@PAC4VG latex.

\section{Resole-Type Phenol-Aldehyde Resins}

The availability of the phenol moieties on the surface of the deprotected core-shell latex particles was demonstrated using the reaction with glyoxal, a water-soluble, naturally-sourced dialdehyde, ${ }^{32}$ to form a resole-type resin. The deprotected latex was mixed with glyoxal in a 1:1 aldehyde:phenol molar ratio, and $\mathrm{KOH}$ (10 wt. \% solution) as basic catalyst at $4 \mathrm{wt}$. \% of polymer. The reaction mixture was placed in aluminum pans and cured in a ventilated oven for 2 hours at $60{ }^{\circ} \mathrm{C}, 2$ hours at $120^{\circ} \mathrm{C}$, and 1 hour at $140{ }^{\circ} \mathrm{C}$. This treatment resulted in a solid and brittle polymer likely due to the high content of aromatic groups. A control experiment consisting of only the deprotected latex (no aldehyde) was also subjected to the same heat treatment. The cured samples were subsequently immersed in THF for 24 hours. As expected, the control sample dissolved completely in THF, while the sample that contained glyoxal did not. A total gel content of $66 \%$ was measured for the latex cured with glyoxal. Crosslinking was also confirmed by FTIR, which showed a $67 \%$ decrease of the 
phenol band (aromatic $-\mathrm{OH}$ band at $3000-3500 \mathrm{~cm}^{-1}$. The spectra were normalized with respect to the $\mathrm{v}_{\mathrm{C}=\mathrm{C}}$ stretching of the aromatic ring at $1550-1610 \mathrm{~cm}^{-1}$ ) in the phenol-aldehyde resin compared to the control sample (see Figure S8).

\section{Conclusion}

The synthesis of novel functional core-shell polymer latexes consisting of $n$-butyl acrylate and styrene with a recently developed biobased monomer, acetyl-protected 4-vinylguaiacol (AC4VG), is presented. High monomer conversions (>95\%) were achieved at the end of the two-step seeded emulsion polymerizations, carried out with ammonium persulfate as initiator and sodium dodecyl sulfate as surfactant, yielding colloidally stable P(S-CO-BA)@PAC4VG and PBA@PAC4VG latexes at $10 \mathrm{wt}$. \% solids content. The semi-continuous addition of the AC4VG monomer resulted in polymer particles with core-shell and partially encapsulated morphologies with intensity-average hydrodynamic diameters of $80-90 \mathrm{~nm}$. DSC analysis revealed the distinct glass transition temperatures corresponding to the individual components in the final polymer latex, indicating that separate polymer phases were formed. The particle morphologies observed by TEM for PBA@PAC4VG were in agreement with theoretical predictions based on thermodynamic and kinetic driving forces. Functional core-shell particles were then obtained by deprotection of up to $70 \%$ of the acetoxy groups of PAC4VG under mild basic conditions. The availability of phenol groups present on the surface of the partially biobased core-shell latex was demonstrated via the crosslinking reaction with glyoxal, a naturally-sourced dialdehyde, to give a resole-type phenolic resin. These results are promising for the use of biobased styrenic derivatives in the development of fully biobased functional latexes and materials. This work serves as a proof-of-concept for the future development of fully biobased, core-shell particles for applications in crosslinked films and coatings.

\section{Conflicts of interest}

There are no conflicts to declare.

\section{References}

1. Stutman, D. R., Klein, A., El-Aasser, M. S., Vanderhoff, J. W. Ind. Eng. Chem. Prod. Res. Dev., 1985, 24, 404-412.

2. Daniel, J.-C., Pichot, C. Les latex synthétiques: élaboration et application, Tec \& Doc Lavoisier, 2006. 
3. Van Herk, A. Chemistry and Technology of Emulsion Polymerisation, Blackwell Publishing Ltd, Oxford, 1st Editio., 2005.

4. Ghosh Chaudhuri, R., Paria, S. Chem. Rev., 2012, 112, 2373-2433.

5. Okubo, M. Makromol. Chemie. Macromol. Symp., 1990, 35-36, 91-103.

6. Musyanovych, A., Landfester, K. In Macromolecular Engineering: Precise Synthesis, Materials Properties, Applications, K. Matyjaszewski, , Y. Gnanou, and L. Leible, Eds.; Wiley- VCH Verlag GmbH \& Co. KGaA, Weinheim Volume 2. 2007; p. 1209.

7. Stubbs, J. M., Sundberg, D. C. Polymer (Guildf)., 2005, 46, 1125-1138.

8. Ramli, R. A., Laftah, W. A., Hashim, S. RSC Adv., 2013, 3, 15543-15565.

9. Bai, L., Gu, J., Huan, S., Li, Z. RSC Adv., 2014, 4, 27363-27380.

10. Dimonie, V. L., Lovell, P. A., El-Aasser, M. S. In Emulsion Polymerization and Emulsion Polymers 1997; p. 293.

11. Hendrickson, G. R., Smith, M. H., South, A. B., Lyon, L. A. Adv. Funct. Mater., 2010, 20, 16971712.

12. Feng, H., Tang, L., Zeng, G., Tang, J., Deng, Y., Yan, M., Liu, Y., Zhou, Y., Ren, X., Chen, S. J. Mater. Chem. A, 2018, 6, 7310-7337.

13. Lee, C. F. Polymer (Guildf)., 2000, 41, 1337-1344.

14. Li, S., Wu, Q., Zhu, H., Lin, Q., Wang, C. Polymers (Basel)., 2017, 9, 684-695.

15. Bentley, J. In Paint and Surface Coatings: Theory and Practice, R. Lambourne, and T. A. Strivens, Eds.; Woodhead Publishing Ltd, Cambridge 2nd edn. 1999; p. 19.

16. Lapeyre, V., Ancla, C., Catargi, B., Ravaine, V. J. Colloid Interface Sci., 2008, 327, 316-323.

17. Buter, R., Postma, P. M.0 469646 A1 1990.

18. Hiemenz, P. C., Rajagopalan, R. Principles of Colloid and Surface Chemistry, Marcel Dekker, New York, Revised an., 1997.

19. Thickett, S. C., Gilbert, R. G. Polymer (Guildf)., 2007, 48, 6965-6991.

20. Tang, J., Ding, T., Daniels, E. S., Dimonie, V. L., Klein, A., El-Aasser, M. S. J. Appl. Polym. Sci., 2003, 88, 30-41.

21. Takeshima, H., Satoh, K., Kamigaito, M. Macromolecules, 2017, 50, 4206-4216.

22. Satoh, K. Polym. J., 2015, 47, 527-536.

23. Demchuk, Z., Shevchuk, O., Tarnavchyk, I., Kirianchuk, V., Lorenson, M., Kohut, A., Voronov, S., Voronov, A. ACS Omega, 2016, 1, 1374-1382.

24. Moreno, M., Goikoetxea, M., De La Cal, J. C., Barandiaran, M. J. J. Polym. Sci. Part A Polym. Chem., 2014, 52, 3543-3549.

25. Hu, L., Pan, H., Zhou, Y., Zhang, M. BioResources, 2011, 6, 3515-3525.

26. Bu, Q., Lei, H., Wang, L., Wei, Y., Zhu, L., Zhang, X., Liu, Y., Yadavalli, G., Tang, J. Bioresour. Technol., 2014, 162, 142-147.

27. Li, J., Zhang, J., Zhang, S., Gao, Q., Li, J., Zhang, W. Polymers (Basel)., 2017, 9, 428-444.

28. Rosazza, J. P. N., Huang, Z., Dostal, L., Volm, T., Rousseau, B. J. Ind. Microbiol., 1995, 15, $472-$ 479. 
29. Ladmiral, V., Jeannin, R., Fernandes Lizarazu, K., Lai-Kee-Him, J., Bron, P., Lacroix-Desmazes, P., Caillol, S. Eur. Polym. J., 2017, 93, 785-794.

30. Li, W. S. J., Negrell, C., Ladmiral, V., Lai-Kee-Him, J., Bron, P., Lacroix-Desmazes, P., JolyDuhamel, C., Caillol, S. Polym. Chem., 2018, 9, 2468-2477.

31. Hatakeyama, T., Nakamura, K., Hatakeyama, H. Polymer, 1978, 19, 593-594.

32. Ramires, E. C., Megiatto, J. D., Gardrat, C., Castellan, A., Frollini, E. Bioresour. Technol., 2010, 101, 1998-2006.

33. González-Ortiz, L. J., Asua, J. M. Macromolecules, 1995, 28, 3135-3145.

34. Wu, S. J. Polym. Sci. Part C Polym. Symp., 1971, 34, 19-30.

35. Owens, D. K., Wendt, R. C. J. Appl. Polym. Sci., 1969, 13, 1741-1747.

36. Stubbs, J. M., Sundberg, D. C. Prog. Org. Coatings, 2008, 61, 156-165.

37. Bréchet, Y., Cavaillé, J. Y. Y., Chabert, E., Chazeau, L., Dendievel, R., Flandin, L., Gauthier, C. Adv. Eng. Mater., 2001, 3, 571-577.

38. Oliveira, R. N., Mancini, M. C., de Oliveira, F. C. S., Passos, T. M., Quilty, B., Thiré, R. M. da S. M., McGuinness, G. B. Rev. Mater., 2016, 21, 767-779.

39 Tonnar, J Lacroix-Desmazes, P, Angew. Chem. Int. Ed. 2008, 47, 1294 -1297. 


\section{Supporting Information}

\section{Ferulic acid-based reactive core-shell latex by seeded emulsion polymerization}

W. S. J. Li $^{a}$, V. Ladmiral ${ }^{a}$, H. Takeshima ${ }^{b}$, K. Satoh ${ }^{b}$, M. Kamigaito ${ }^{b}$, M. Semsarilar ${ }^{c}$, C. Negrell ${ }^{a}$, P. Lacroix-Desmazes $^{a}$, S. Caillol ${ }^{a^{*}}$

a ICGM, Université de Montpellier, CNRS, ENSCM, Montpellier, France.

${ }^{b}$ Department of Molecular and Macromolecular Chemistry, Graduate School of Engineering, Nagoya University, Nagoya 464-8603, Japan.

${ }^{c}$ Institut Européen des Membranes (UMR 5635, ENSCM-CNRS-UM), Université de Montpellier, C.C. 047, Place E. Bataillon, Montpellier, France.

\section{Determination of AC4VG conversion}

AC4VG monomer conversions were calculated by ${ }^{1} \mathrm{H}$ NMR using the following equation:

$$
\text { conversion }(A C 4 V G)=100 \times\left[1-\frac{\left(\frac{\int_{5.18}^{5.28} C H(A C 4 V G)_{t} / 1}{\int_{0.72}^{1.01} C H_{3}(P B A)_{t} / 3}\right)}{\left(\frac{\int_{5.18}^{5.8} C H(A C 4 V G)_{t=0} / 1}{\int_{0.72}^{1.01} C H_{3}(P B A)_{t=0} / 3}\right)}\right]
$$

\section{Determination of the number of particles in the seed latex and in the composite latex}

The number of particles in the seed and final latexes were calculated as follows:

The mass of one polymer particle is calculated as:

where,

$$
m_{\text {polymer particle }}=\frac{\pi}{6}\left(D_{v}\right)^{3} \rho
$$

$$
\begin{aligned}
& D_{v} \text { is the volume-average particle diameter } \\
& \rho \text { is the polymer density }
\end{aligned}
$$

The number of particles in a given quantity of latex is calculated as:

where,

$$
N_{p}=\frac{m_{\text {polymer }}}{m_{\text {polymer particle }}}
$$

$$
\begin{aligned}
& m_{\text {polymer }} \text { is the mass of polymer in the latex } \\
& m_{\text {polymer particle is the mass of one polymer particle }}
\end{aligned}
$$

For the $\mathrm{P}(\mathrm{S}-\mathrm{co}-\mathrm{BA})$ latex, using the volume-intensity average diameter of $55 \mathrm{~nm}$, as measured by DLS,

$$
m_{P(S \text {-co-BA }) \text { particle }}=\frac{\pi}{6}(55 \mathrm{~nm})^{3}\left(\frac{1.058 \mathrm{~g}}{\mathrm{~cm}^{3}}\right)\left(\frac{10^{-7} \mathrm{~cm}}{\mathrm{~nm}}\right)^{3}=9.2 \times 10^{-17} \mathrm{~g}
$$

In $16 \mathrm{~g}$ of $\mathrm{P}(\mathrm{S}-\mathrm{CO}-\mathrm{BA})$ seed latex at $8 \mathrm{wt}$. \% solids content,

$$
N_{p} \text { in } P(S \text {-co- } B A) \text { seed latex }=\frac{(16 g)(0.08)}{9.2 \times 10^{-17} \mathrm{~g}}=1.4 \times 10^{16}
$$

For the P(S-Co-BA)@PAC4VG latex, using the volume-intensity average diameter of $74 \mathrm{~nm}$, as measured by DLS, 


$$
m_{P(S \text {-co-BA }) @ P A C 4 V G \text { particle }}=\frac{\pi}{6}(74 \mathrm{~nm})^{3}\left(\frac{1.022 \mathrm{~g}}{\mathrm{~cm}^{3}}\right)\left(\frac{10^{-7} \mathrm{~cm}}{\mathrm{~nm}}\right)^{3}=2.2 \times 10^{-16} \mathrm{~g}
$$

With the near complete conversion of $2 \mathrm{~g}$ of AC4VG in the seed latex,

$$
N_{p} \text { in } P(S \text {-co-BA }) @ P A C 4 V G \text { latex }=\frac{(16 g)(0.08)+2 g}{2.2 \times 10^{-16} g}=1.5 \times 10^{16}
$$

For the PBA latex, using the volume-intensity average diameter of $60 \mathrm{~nm}$ as measured by DLS,

$$
m_{P B A \text { particle }}=\frac{\pi}{6}(60 \mathrm{~nm})^{3}\left(\frac{1.087 \mathrm{~g}}{\mathrm{~cm}^{3}}\right)\left(\frac{10^{-7} \mathrm{~cm}}{\mathrm{~nm}}\right)^{3}=1.2 \times 10^{-16} \mathrm{~g}
$$

In $15 \mathrm{~g}$ of PBA seed latex at 8 wt. \% solids,

$$
N_{p} \text { in PBA seed latex }=\frac{(15 \mathrm{~g})(0.08)}{1.2 \times 10^{-16} \mathrm{~g}}=1.0 \times 10^{16}
$$

For the PBA@PAC4VG latex, using the volume-intensity average diameter of $91 \mathrm{~nm}$, as measured by DLS,

$$
m_{P B A @ P A C 4 V G \text { particle }}=\frac{\pi}{6}(90 \mathrm{~nm})^{3}\left(\frac{1.026 \mathrm{~g}}{\mathrm{~cm}^{3}}\right)\left(\frac{10^{-7} \mathrm{~cm}}{\mathrm{~nm}}\right)^{3}=4.0 \times 10^{-16} \mathrm{~g}
$$

With the near complete conversion of $3 \mathrm{~g}$ of AC4VG in the seed latex,

$$
N_{p} \text { in PBA@PAC4VG latex }=\frac{(15 g)(0.08)+3 g}{4.0 \times 10^{-16} g}=1.1 \times 10^{16}
$$

\section{Determination of the interfacial tensions}

The interfacial tensions of the polymers were calculated using $\mathrm{Wu}^{\prime}$ 's method ${ }^{34}$ :

$$
\gamma_{i j}=\gamma_{i}+\gamma_{j}-\left[\frac{4 \gamma_{i}^{P} \gamma_{j}^{P}}{\gamma_{i}^{P}+\gamma_{j}^{P}}\right]-\left[\frac{4 \gamma_{i}^{D} \gamma_{j}^{D}}{\gamma_{i}^{D}+\gamma_{j}^{D}}\right]
$$

$\gamma_{\mathrm{ij}}$ is the interfacial surface tension between species $i$ and species $j$

$\gamma_{i}^{\mathrm{P}}, \gamma_{i}^{\mathrm{D}}$ and $\gamma_{j}^{\mathrm{P}}, \gamma_{j}^{\mathrm{D}}$ are the polar and dispersion components of the surface tension of species $i$ and $j$ respectively

$\gamma_{i}$ and $\gamma_{j}$ are the total surface tensions of species $i$ and $j$ respectively $\left(\gamma_{i}^{p}+\gamma_{i}^{D}=\gamma_{i}\right)$

In order to use Wu's method, the polar and dispersion components of the surface tensions of each solid species were calculated using Owen's equation ${ }^{35}$ (Equation S5; here $\gamma_{i}^{p}$ and $\gamma_{i}^{D}$ are denoted as $\gamma_{s}{ }^{p}$ and $\gamma_{s}{ }^{D}$ in reference to the solid polymer species) by using the measured contact angles of a polar $\left(\mathrm{H}_{2} \mathrm{O}\right)$ and a non-polar $\left(\mathrm{CH}_{2} \mathrm{I}_{2}\right)$ liquid on the surface of each polymer.

$$
1+\cos \theta=2 \sqrt{\gamma_{S}^{D}}\left(\frac{\sqrt{\gamma_{l}^{D}}}{\gamma_{l v}}\right)+2 \sqrt{\gamma_{S}^{P}}\left(\frac{\sqrt{\gamma_{l}^{P}}}{\gamma_{l v}}\right)
$$

$\gamma_{s}{ }^{D}$ and $\gamma_{s}{ }^{p}$ are the dispersion and polar components of the surface free energy of the solid species $\nu_{1}^{D}$ and $\gamma_{1}{ }^{\mathrm{P}}$ are the dispersion and polar components of the surface free energy of the liquid species $\gamma_{\mathrm{IV}}$ is the free energy of the liquid species against its saturated vapor 
$\theta$ is the contact angle (in degrees) of the liquid species against a solid species

The values of $\gamma_{1}^{D}, \gamma_{1}^{P}$ and $\gamma_{1 v}$ were taken from the literature for water $\left(\gamma_{1}^{D}=21.8\right.$ dynes $/ \mathrm{cm}, \gamma_{1}^{P}=51$ dynes $/ \mathrm{cm}$, and $\gamma_{\mathrm{lv}}=72.8$ dynes $\left./ \mathrm{cm}\right)$ and diiodomethane $\left(\gamma_{1}^{\mathrm{D}}=49.5 \mathrm{dynes} / \mathrm{cm}, \gamma_{1}^{\mathrm{P}}=1.3 \mathrm{dynes} / \mathrm{cm}\right.$, and $V_{\mathrm{lv}}=50.8$ dynes $/ \mathrm{cm}$ ). ${ }^{35}$ A system of two equations (one equation for each contact angle of each liquid) with two unknowns $\left(\gamma_{s}{ }^{\mathrm{P}}\right.$ and $\left.\gamma_{s}{ }^{\mathrm{D}}\right)$ can then be solved to obtain the values of $\gamma_{s}{ }^{\mathrm{P}}$ and $\gamma_{s}{ }^{\mathrm{D}}$ for each polymer component. These values were then used in Equation $\$ 4$ to obtain the respective interfacial tensions.

Table S1: Measured contact angles of water and methylene iodide on various polymer surfaces.

\begin{tabular}{|c|c|c|c|c|c|}
\hline Material & $\begin{array}{c}\text { Water contact } \\
\text { angle }\left(^{\circ}\right)\end{array}$ & $\begin{array}{c}\text { Methylene iodide } \\
\text { contact angle }\left(^{\circ}\right)\end{array}$ & $\begin{array}{c}\gamma_{\mathrm{s}} \\
(\text { dyne/cm) }\end{array}$ & $\begin{array}{c}\gamma_{\mathrm{s}}{ }^{\mathrm{P}} \\
(\mathrm{dyne} / \mathrm{cm})\end{array}$ & $\begin{array}{c}\gamma_{\mathrm{s}}{ }^{\mathrm{D}} \\
(\mathrm{dynne} / \mathrm{cm})\end{array}$ \\
\hline PBA & $97.1 \pm 0.1^{*}$ & $64.5 \pm 0.1^{*}$ & 26.0 & 1.5 & 24.5 \\
\hline PAC4VG & $85.7 \pm 0.1$ & $39.3 \pm 0.1$ & 40.1 & 2.1 & 38.0 \\
\hline (P(S-co-BA) & $98.5 \pm 0.1$ & $40.0 \pm 0.1$ & 42.5 & 0.0 & 42.5 \\
\hline BA)@PAC4VG & $75.1 \pm 0.1$ & $50.9 \pm 0.1$ & & & \\
\hline PBA@PAC4VG & $89.5 \pm 0.1$ & $68.2 \pm 0.1$ & & & \\
\hline
\end{tabular}

${ }^{*}$ value taken from Kim et al. ${ }^{40}$

Table S2: Interfacial tensions and parameters $U$ and T calculated according to the method of Gonzales-Ortiz. ${ }^{33}$

\begin{tabular}{|c|c|c|c|c|c|}
\hline Polymer & $\begin{array}{c}\gamma_{12} \\
\text { (dyne/cm) }\end{array}$ & $\begin{array}{c}\gamma_{1 \mathrm{w}} \\
\text { (dyne/cm) }\end{array}$ & $\begin{array}{c}\gamma_{2 \mathrm{w}} \\
\text { (dyne/cm) }\end{array}$ & $\mathrm{T}$ & $\mathrm{U}$ \\
\hline P(S-co-BA)@PAC4VG & 2.3 & 57.1 & 48.9 & 0.82 & 0.05 \\
\hline PBA@PAC4VG & 3.0 & 46.5 & 48.9 & 0.99 & 0.06 \\
\hline
\end{tabular}

*1=P(S-co-BA) or PBA, 2=PAC4VG, W=water 


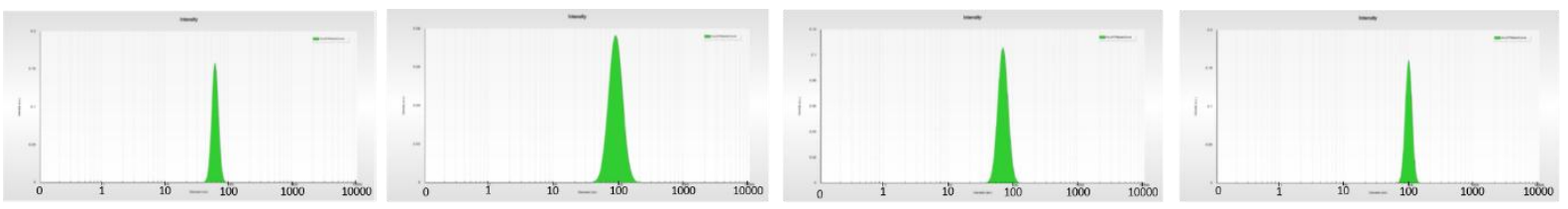

Figure S1: Intensity-average particle hydrodynamic diameters distributions for (from left to right): $P\left(S_{85}-\mathrm{CO}_{-} B A_{15}\right),\left(P\left(S_{37}-\mathrm{CO}-\right.\right.$ $\left.B A_{6}\right) @ P A C 4 V G_{57}, P B A$, and $P B A_{30} @ P A C 4 V G_{70}$. The subscripts indicate the monomer weight fractions.
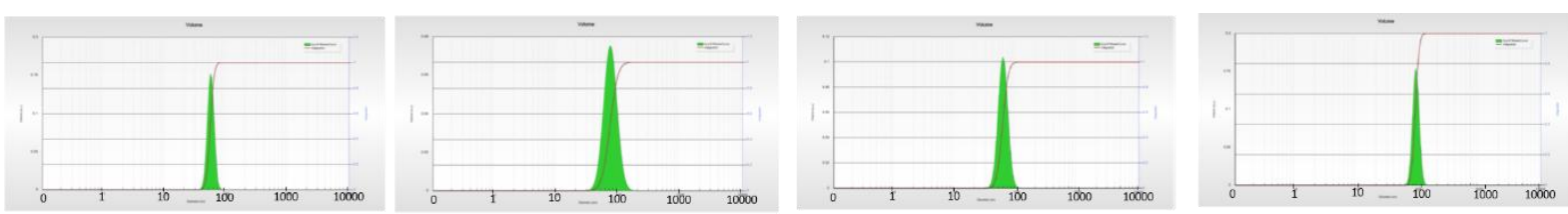

Figure S2: Volume-average particle size distributions for (from left to right): $P\left(S_{85}-\mathrm{Co}-B A_{15}\right),\left(P\left(S_{37}-\mathrm{Co}-B A_{6}\right) @ P A C 4 V G_{57}, P B A\right.$, and $P B A_{30} @ P A C 4 V G_{70}$. The subscripts indicate the monomer weight fractions.
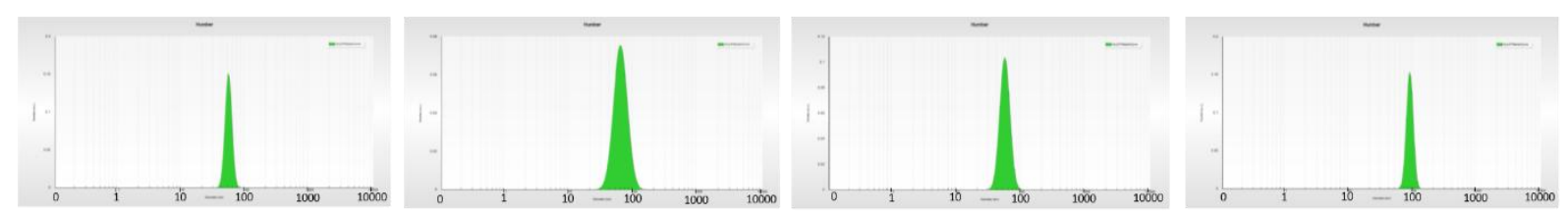

Figure S3: Number-average particle size distributions for (from left to right): $P\left(S_{85}-\mathrm{Co}-B A_{15}\right),\left(P\left(S_{37}-\mathrm{co}-B A_{6}\right) @ P A C 4 V G_{57}, P B A\right.$, and $P B A_{30} @ P A C 4 V G_{70}$. The subscripts indicate the monomer weight fractions.

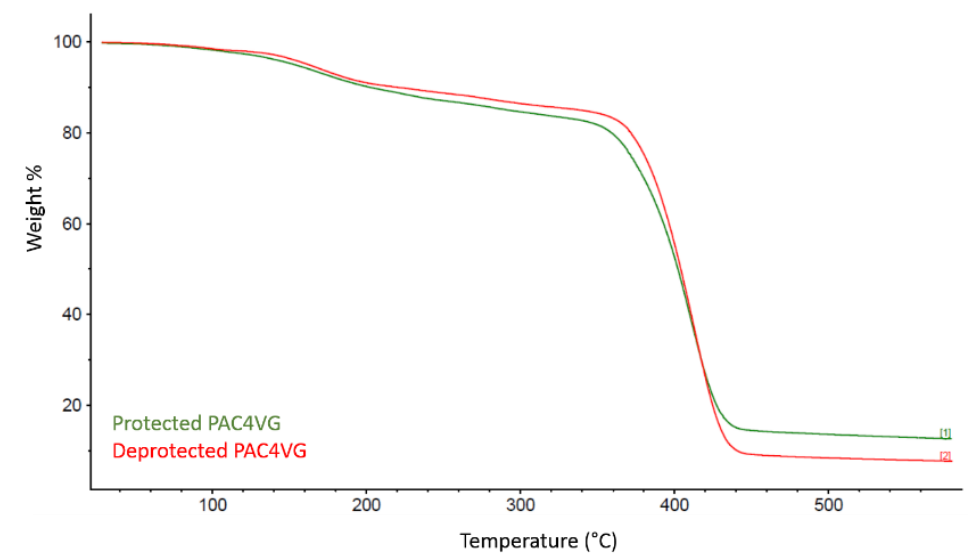

Figure S4: TGA thermograms of protected and deprotected PAC4VG.

Estimation of a copolymer $T_{\mathrm{g}}$ based on the $T_{\mathrm{g}}$ of the pure components using the Fox-Flory equation:

where,

$$
\frac{1}{T_{g, \text { copolymer }}}=\frac{w_{1}}{T_{g, 1}}+\frac{w_{2}}{T_{g, 2}}
$$

$\mathrm{w}_{1}$ and $\mathrm{w}_{2}$ are the weight fractions of polymers 1 and 2

$T_{\mathrm{g}, 1}$ and $T_{\mathrm{g}, 2}$ are the individual glass transition temperatures of polymers 1 and 2 (in Kelvin) 


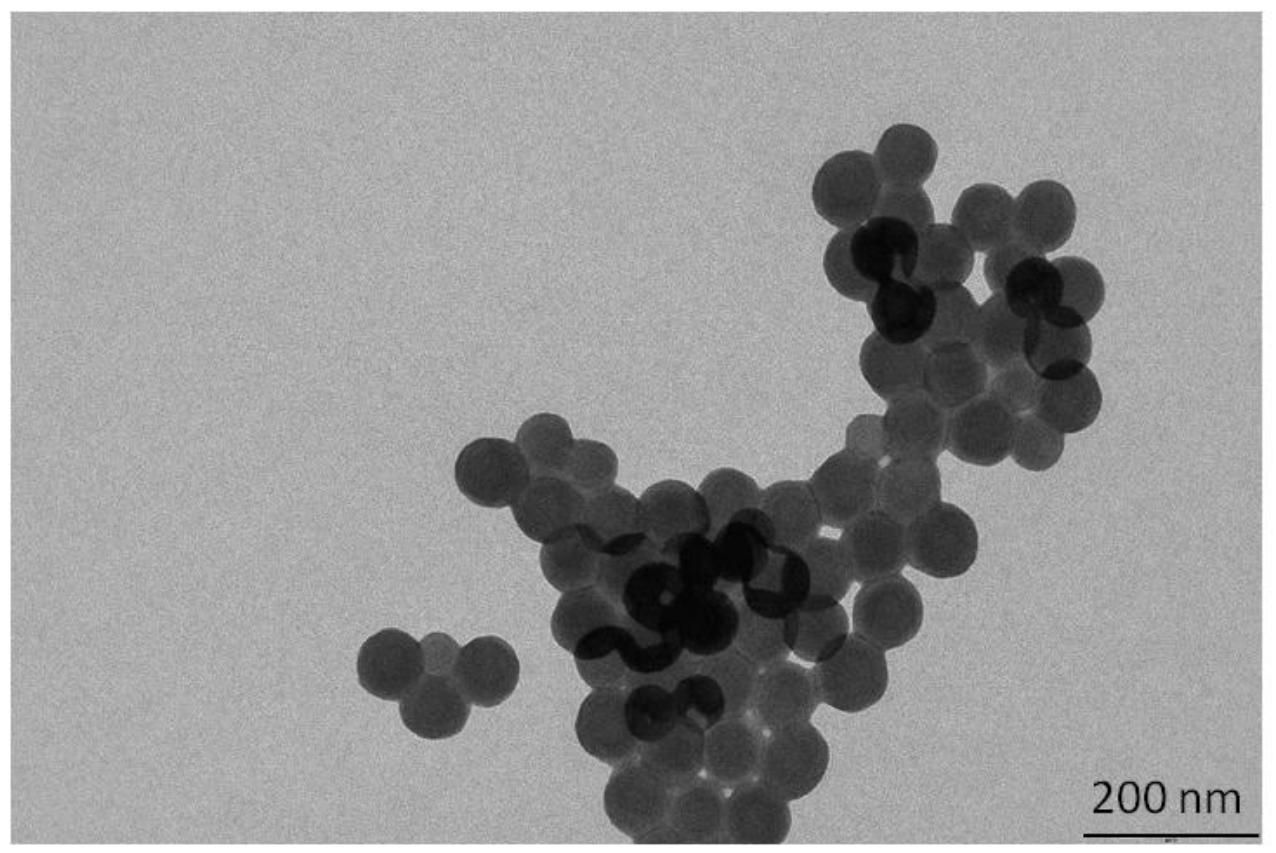

Figure S5 : TEM image of P(S-Co-BA)@PAC4VG latex particles.

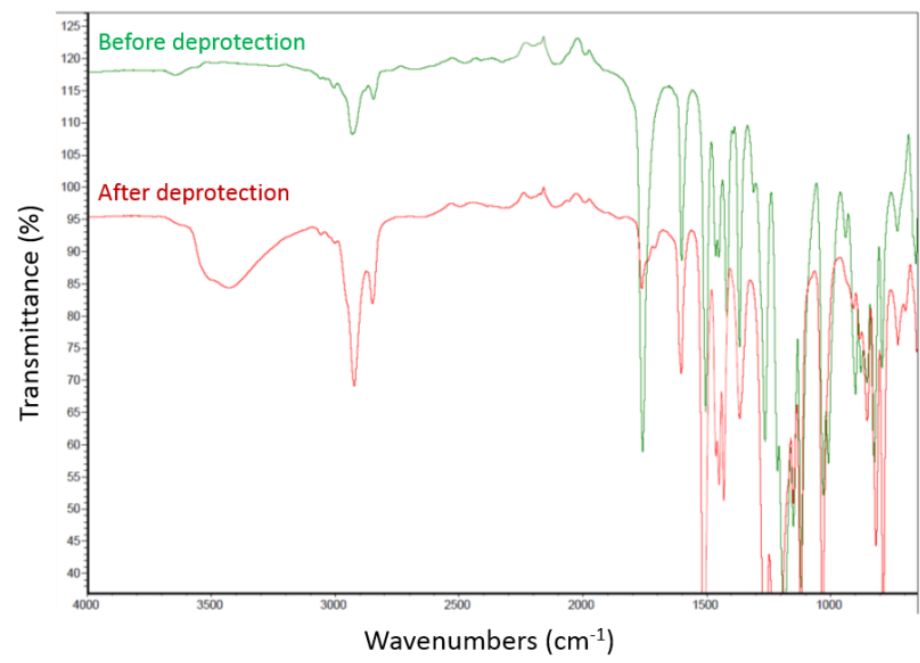

Figure S6: FTIR analysis of PAC4VG before and after deprotection. 


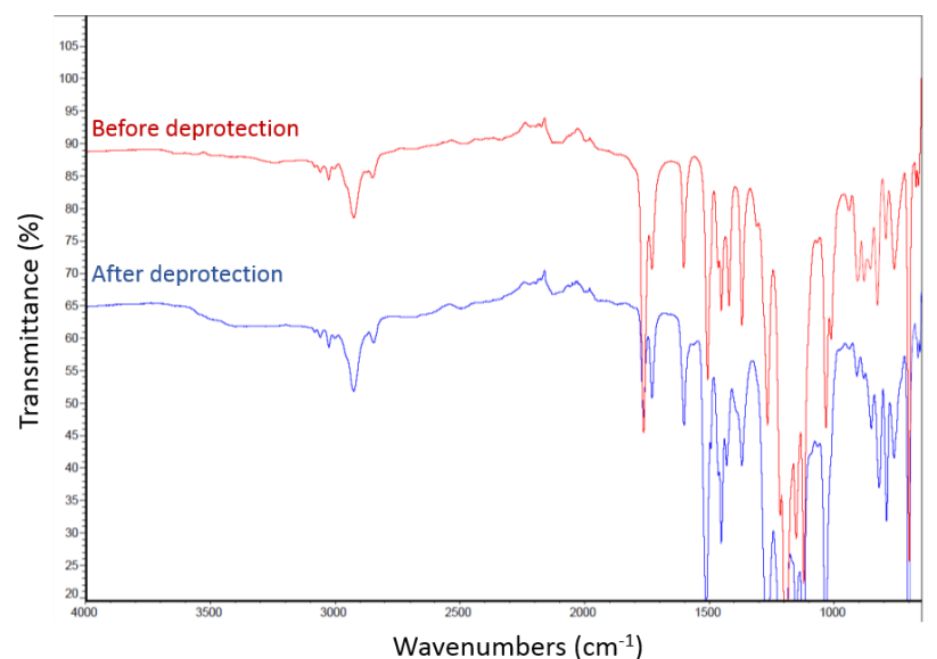

Figure S7: FTIR analysis of P(S-co-BA)@PAC4VG before and after deprotection.

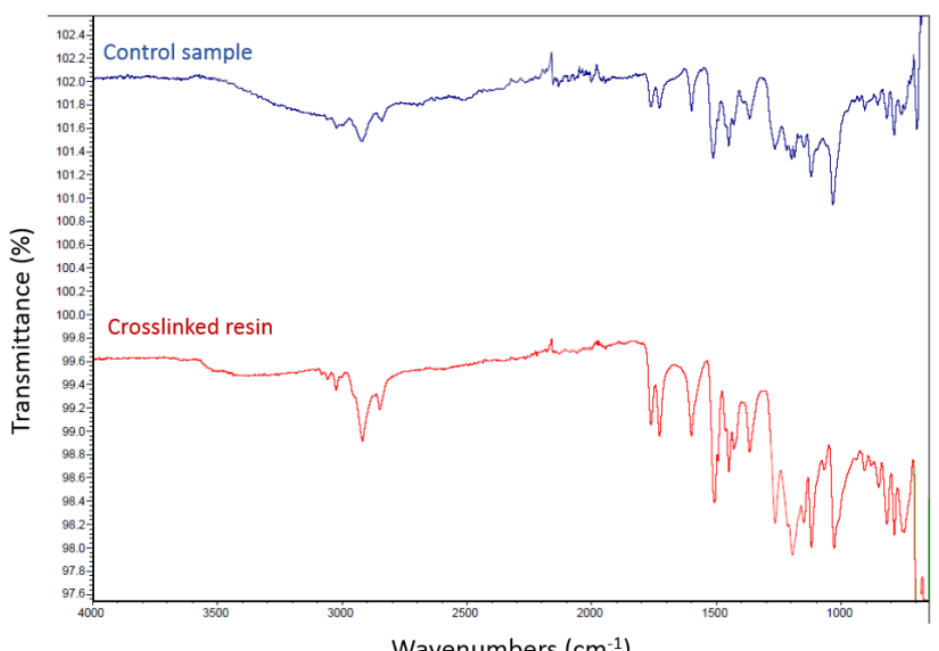

Figure S8: FTIR analysis of control sample (non-crosslinked) and crosslinked resin. 